\title{
The Complex Compound of Amino Acids With Titanium (III) as a Method to Control and Synthesis of Different Structures of TiO2 Nanoparticles; Usage as Photocatalysts to Oxidize Alcohols to Aldehyde
}

Yahya Absalan ( $\nabla$ yahyaabsalan2014@gmail.com )

Faculty of Science, Ferdowsi University of Mashhad https://orcid.org/0000-0003-2738-9645

Nazanin Noroozi Shad

Faculty of Science, Ferdowsi University of Mashhad

Mostafa Gholizadeh

Faculty of Science, Ferdowsi University of Mashhad

Original Research Full Papers

Keywords: acid amino, TiO2, organometallic, nanoparticle, photocatalytic- oxidation, alcohol

Posted Date: February 4th, 2021

DOl: https://doi.org/10.21203/rs.3.rs-175630/v1

License: (1) (i) This work is licensed under a Creative Commons Attribution 4.0 International License.

Read Full License 


\title{
The complex compound of amino acids with Titanium (III) as a method to control and synthesis of different structures of $\mathrm{TiO}_{2}$ nanoparticles; usage as photocatalysts to oxidize alcohols to aldehyde
}

\author{
Yahya Absalan*a, Nazanin Noroozi Shad ${ }^{\text {a }}$, Mostafa Gholizadeh* a
}

${ }^{a}$ Department of Chemistry, Faculty of Science, Ferdowsi University of Mashhad, Mashhad, I.R.Iran *Corresponding author: Yahya Absalan \& Mostafa Gholizadeh: yahyaabsalan2014@gmail.com,
+989011688148

Mostafa Gholizadeh: m_gholizadeh@um.ac.ir, +989153516148

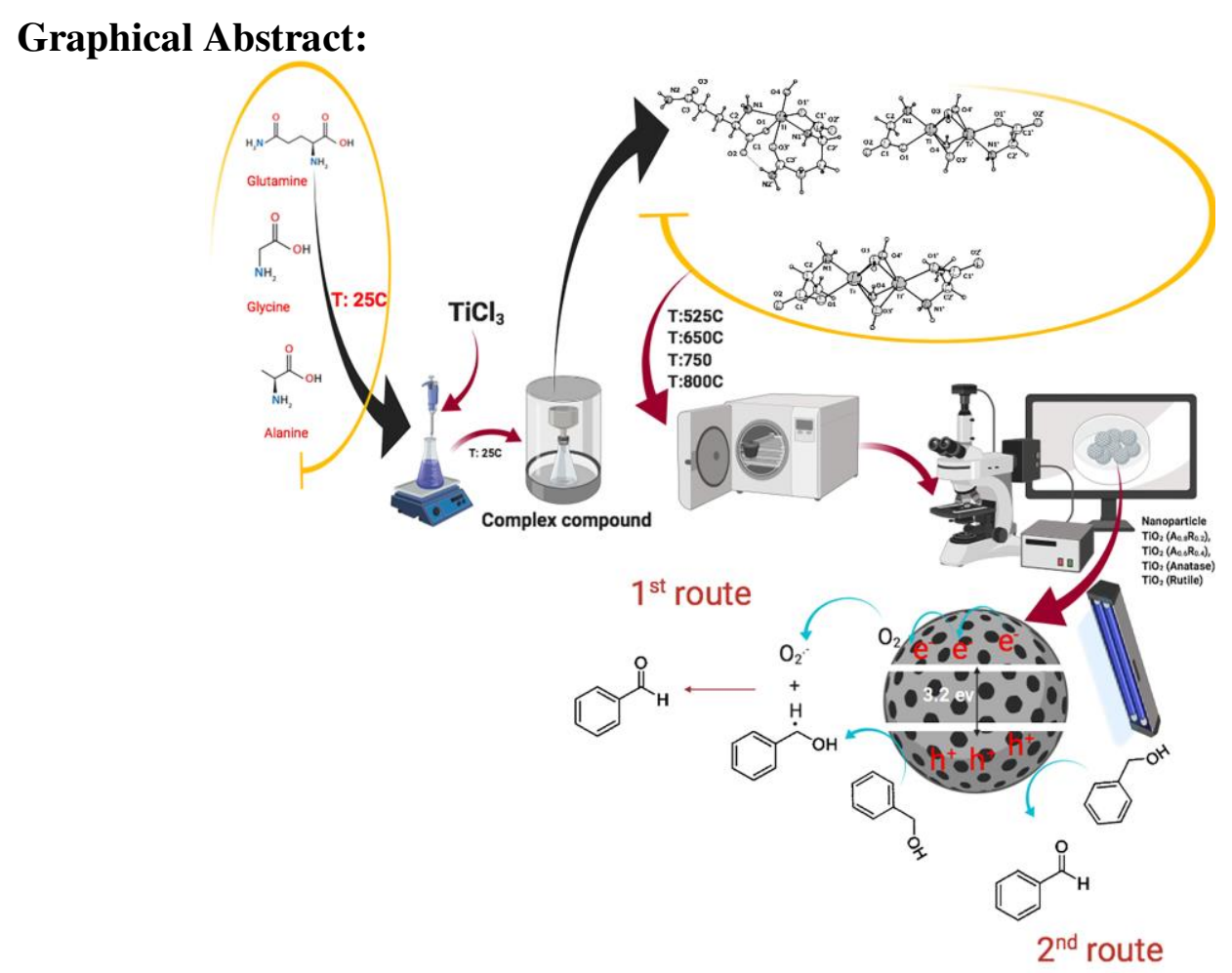

Highlights:

$>$ Synthesizing complex compounds of titanium chloride (III) with different derivatives of amino acids for the first time

$>$ Controlling and synthesizing $\mathrm{TiO}_{2}$ in different structures with high purity and porosity

$>$ Photocatalytic ability of $\mathrm{TiO}_{2}$ for converting alcohols oxidize to corresponding aldehydes 


\begin{abstract}
Different types of the amino acids (Glutamine, Glycine, Alanine) were used to coordinate $\mathrm{TiCl}_{3}$ in order to investigating the best precursor for synthesis of $\mathrm{TiO}_{2}$. Also, a full investigation was carried out to synthesis four different structures of $\mathrm{TiO}_{2}$ nanoparticles

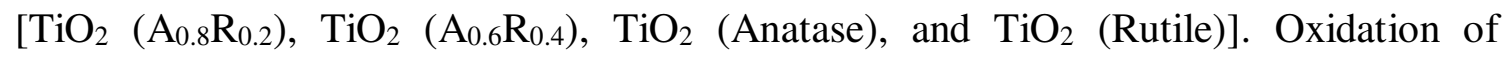
derivatives alcohol to their corresponding aldehyde through the obtained nanoparticles, as a photocatalyst, under UV light was considered to investigate the best structure of $\mathrm{TiO}_{2}$. Different physical-chemical analyses were applied to investigate the result. The result showed that the titanium dioxide nanoparticle, synthesized from glycine was obtained at the least temperature and was chosen as a precursor to synthesis of four different types of $\mathrm{TiO}_{2}$. All the synthesized $\mathrm{TiO}_{2}$ were applied for oxidation of benzyl alcohols into benzaldehyde, as a test, and $\mathrm{TiO}_{2}\left(\mathrm{~A}_{0.6} \mathrm{R}_{0.4}\right)$ could give the best result (87\% efficiency). Then it was used to oxidize benzyl alcohol, 4-cholorobenzyl alcohol, 4-nitrobenzyl alcohol and 4-methoxybenzyl alcohol to their corresponding aldehyde and efficiency were $74,92,87$, and $65 \%$ respectively.
\end{abstract}

Keywords: acid amino; $\mathrm{TiO}_{2}$; organometallic; nanoparticle; photocatalytic- oxidation; alcohol

\title{
1. Introduction
}

Titanium dioxide nanoparticles in different ratios have found their place among all types of nanoparticles and they are used in different applications such as painting, catalyst, photocatalyst, solar energy, food, beverages, and pharmaceutical industries etc [1-8].

Many methods have been created by scientists for the synthesis of titanium dioxide nanoparticles, including sol-gel, microwave, micelle, aerogel, hydrothermal, chemical vapour deposition, physical vapour deposition, electrochemical accumulation, sonochemical, and microwave. Organometallic complex compounds are also proper initial products for the synthesis of nanoparticles, with the advantages of low temperature, less time, purity, and environmentally friendly [9-16].

Amino acids are natural substances with a low-temperature melting point, soluble in water, and also they have an active side to make complex compounds with titanium ions, so they are active and effective ligands to synthesize complex compounds of titanium. Titanium 
dioxide obtained from these types of complex compounds can be obtained at low temperature and less time with high purity [17].

Amino acids have different categories, specifying with their side chains, including amino acids with electrically charged side chains, amino acids with polar uncharged side chain, amino acids with hydrophobic side chain, and special case.

On the other hand, titanium dioxide nanoparticle has different phases and structures, including anatase, brookite, and rutile. There is also an artificial structure called Degussa, which is made by $80 \%$ anatase and $20 \%$ rutile, and it shows a high ability for different application such as photocatalyst. So they illustrate different abilities based on their molecular structure, and according to these properties, synthesizing $\mathrm{TiO}_{2}$ with different ratio of phases can be very essential, especially when they are used as optical and photocatalyst. The photocatalytic oxidation of alcohols to their corresponding aldehydes has attracted a great deal of interest in several fields of chemistry [18-25]. This is because of the importance of aldehydes in various chemical usages, including drugs, dyes, resins and fragrances[26]. $\mathrm{TiO}_{2}$ nanoparticles, as the most important semiconductor photocatalysts, were confirmed as an effective and selective agent in partial oxidation of benzyl alcohols to corresponding benzaldehydes [27-29]. It has been confirmed that the structure of $\mathrm{TiO}_{2}$ and the adsorbed oxygen molecules on the surface of $\mathrm{TiO}_{2}$, as two essential factors, have strong influences on the selective physicochemical activity[30-32].

Generally, numerous studies have been demonstrated that the photocatalytic activity of bare anatase and rutile $\mathrm{TiO}_{2}$, is lower than that observed for their anatase/rutile composites[33-39]. One of the best examples is the P25 commercial material, containing 70$80 \%$ of anatase and 30-20\% of rutile that produced by Evonik. Moreover, they reported the charge transfer between particles of different phases caused high photoactivity of P25 [4042].

In this study, we focused on the photocatalytic application of titanium oxide nanoparticle in the oxidation reaction of benzyl alcohols into aldehydes, as an especial and important reaction in industries. To this aim, we synthesized nanoparticle of titanium oxide $\left[\mathrm{TiO}_{2}\right.$ with $20 \%$ anatase- $80 \%$ rutile $\left(\mathrm{A}_{0.8} \mathrm{R}_{0.2}\right), \mathrm{TiO}_{2}$ with $60 \%$ anatase-40\% rutile $\left(\mathrm{A}_{0.6} \mathrm{R}_{0.4}\right), \mathrm{TiO}_{2}$ with $100 \%$ anatase $(\mathrm{A})$, and $\mathrm{TiO}_{2}$ with $100 \%$ rutile $(\mathrm{R})$ ] through the complex compounds of amino acids of Glycine, L-Alanine, and glutamine, which belong to the special case, amino acid with hydrophobic side chain, and amino acids with a polar uncharged side chain respectively. For comparison purposes, the home-prepared nano- $\mathrm{TiO}_{2} \mathrm{~S}$ have been applied in the photocatalytic oxidation of benzyl alcohols to the corresponding aldehydes in acetonitrile at 
ambient temperature, under UV irradiation. The partial photocatalytic oxidation of benzyl alcohol, 4-cholorobenzyl alcohol, 4-nitrobenzyl alcohol and 4-methoxybenzyl alcohol to the corresponding aldehydes was investigated with home-prepared nano- $\mathrm{TiO}_{2}$ samples. Also, the influence of the substituent group was studied in the photocatalytic oxidation reaction.

\section{Experiment}

Characterizations. XRD pattern was obtained by GNR Explorer advance using $1.541 \mathrm{~A}(\mathrm{Cu}-$ $\mathrm{Ka}$ ). Firefly 7.1.G software was used for quantum-chemical modelling of the molecule and complex. Synchronous thermal analysis (simultaneous recording of TG and DSC curves) was performed on a Netzsch STA 449 F3 Jupiter installation in air. BET analysis to measure the surface activity of the nanoparticles was carried out by capillary condensation of nitrogen at $77 \mathrm{~K}$ on a micrometric Belsorp-mini II. To estimate the mesoporosity and pore size distribution function, the Barrett-Joyner-Halenda method (BJH) was used. The microscopic images of the nanoparticles were detected by TESCAN BRNO-Mira3 LMU to study the morphology of the nanoparticles, which was accompanied by EDX analysis. TEM images were taken by LEO 912AB through dispersing by ethanol. Estimating the energy bandgap of the nanoparticles was carried out by UV-Vis spectroscopy varian 50. The melting points of the products were determined with an Electrothermal Type 9100 melting point apparatus. FT-IR spectra were recorded on pressed $\mathrm{KBr}$ pellets using an AVATAR 370 FT-IR spectrometer (Therma Nicolet spectrometer, USA) at room temperature in the range between 4000 and $400 \mathrm{~cm}^{-1}$ with a resolution of $4 \mathrm{~cm}^{-1}$. NMR spectra were recorded on an NMR Bruker Avance spectrometer at $300 \mathrm{MHz}$ in $\mathrm{CDCl}_{3}$. Mass spectra were recorded with a $\mathrm{CH} 7 \mathrm{~A}$ Varianmat Bremem instrument at $70 \mathrm{eV}$ electron impact ionization, in $\mathrm{m} / \mathrm{z}$ (rel \%). All yields refer to the isolated products after purification by column chromatography. The photocatalytic oxidation experiments were performed in a capped-sealed test tube equipped with a $100 \mathrm{~W}$ Hg lamp (UVA, UVB Light). The system was cooled by water circulating and the temperature was about $20^{\circ} \mathrm{C}$.

Material. All the main precursor, including ligands and solvents, were purchased from Merck and Sigma-Aldrich and were used as received without further purification. The purity determinations of the products and the progress of the reactions were accomplished by TLC on silica gel Polygram STL G/UV 254 plates. 


\subsection{Synthesis of complexes}

General method. Using 100\% natural-renewable amino acids as ligands, which decomposes at $<550^{\circ} \mathrm{C}$ with high uniformity to synthesize titanium oxide make an advantage of using these types of ligands to use as ligands for making complexes as precursors for obtaining nanoparticle. All the procedure was carried out under a nitrogen atmosphere to avoid any oxidization. Due to using the derivatives of amino acid, as the ligand, the observation was almost the same with a difference in time of different step. Deionized water and methanol with 60 and $40 \%$ were used respectively, as solvents to solve the ligands. Then $\mathrm{NaOH}$ was added to make the environment of the reaction neutral. After that, $\mathrm{TiCl}_{3}$ was added dropwise to make precipitate. The colour was changed from colourless to green and then it changed to blue. Then it stayed for days at room temperature and after some days the blue colour changed to white suspension. The mentioned method was repeated for Glutamine $\left(\mathrm{L}^{1}\right)$, Glycine $\left(\mathrm{L}^{2}\right)$, and L-Alanine $\left(\mathrm{L}^{3}\right)$.

\subsection{Synthesizing nanoparticles of $\mathrm{TiO}_{2}$}

General method. The obtained complex compounds were used as a precursor to isolate titanium oxide nanoparticle of $\mathrm{TiO}_{2}$. Thermal decomposing was the method used to transfer complex compound to the nanoparticles. To test the proper temperature and time, a small amount of the complex compound was analyzed thermally. The following procedure was applied for the TGA analysis (Thermal Gravimetric Analysis).

For this purpose, each complex compound was placed in a closed aluminium crucible and the temperature was set between $25-900{ }^{\circ} \mathrm{C}$. The heating rate was $10 \mathrm{deg} / \mathrm{min}$. According to the obtained result from the analysis and XRD pattern, the product, from the complex of glycine and $\mathrm{TiCl}_{3}\left(\mathrm{ML}^{2}\right)$, was obtained at a lower temperature (around 525C), the obtaining titanium oxide nanoparticle from Glutamine+ $\mathrm{TiCl}_{3}\left(\mathrm{ML}^{1}\right)$ and $\mathrm{L}-\mathrm{Alanin}+\mathrm{TiCl}_{3}\left(\mathrm{ML}^{3}\right)$ was resulted at around $860 \mathrm{C}$ and $900 \mathrm{C}$ respectively. So $\mathrm{ML}^{1}$ was chosen, as the most proper precursor, for obtaining further products, including $\mathrm{TiO}_{2}\left(\mathrm{~A}_{0.8} \mathrm{R}_{0.2}\right), \mathrm{TiO}_{2}\left(\mathrm{~A}_{0.6} \mathrm{R}_{0.4}\right), \mathrm{TiO}_{2}(\mathrm{~A})$, and $\mathrm{TiO}_{2}(\mathrm{R})$.

The mentioned products were obtained by controlling the temperature (Fig.1). $\mathrm{TiO}_{2}(\mathrm{~A})$, as the first phase of $\mathrm{TiO}_{2}$, was obtained at around $525^{\circ} \mathrm{C}, \mathrm{TiO}_{2}\left(\mathrm{~A}_{0.6} \mathrm{R}_{0.4}\right)$ at around $650^{\circ} \mathrm{C}$, $\mathrm{TiO}_{2}\left(\mathrm{~A}_{0.8} \mathrm{R}_{0.2}\right)$ at about $750^{\circ} \mathrm{C}$, and finally, $\mathrm{TiO}_{2}(\mathrm{R})$ was obtained at $800^{\circ} \mathrm{C}$. 


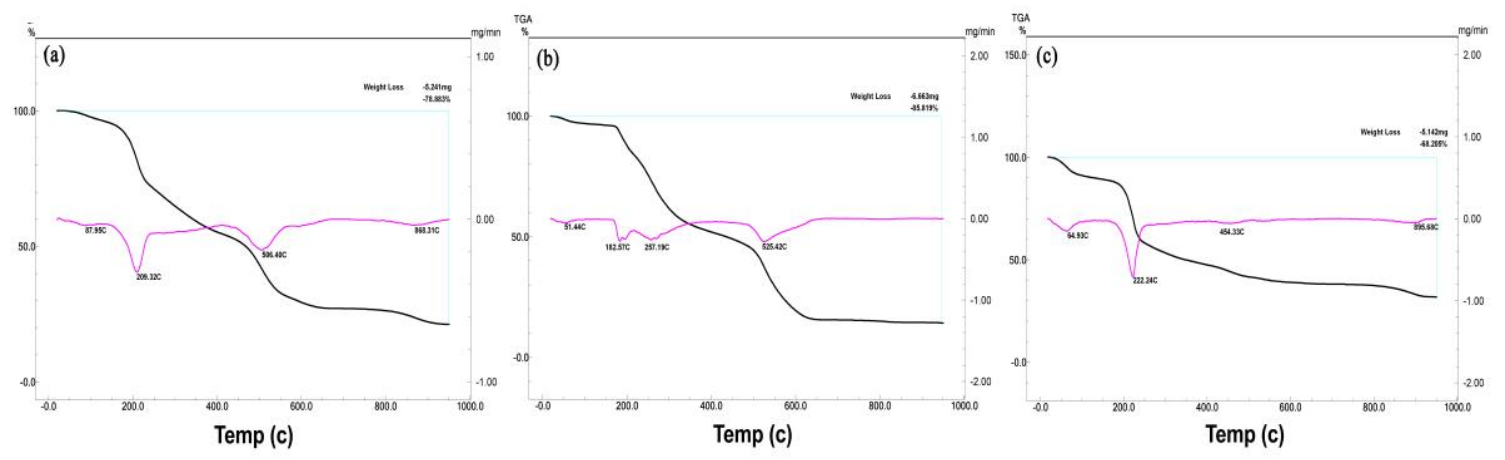

Fig. 1. TGA analysis from the obtained complexes; (a) $\mathrm{ML}^{1}$ (b) $\mathrm{ML}^{2}$, and (c) $\mathrm{ML}^{3}$

2.3. Photocatalytic degradation of some alcohol derivatives to their corresponding aldehydes.

Photo-oxidation reaction was carried out in a capped-sealed test tube containing homeprepared nano- $\mathrm{TiO}_{2}(3 \mathrm{mg})$ suspended in a solution consisting of $2 \mathrm{ml}$ benzyl alcohol ( $\left.1 \mathrm{mmol}\right)$ and acetonitrile as solvent. The mixture was stirred using constant magnetic stirring in different periods under UV light irradiation. The progress of the reaction was monitored by TLC (eluent: n-hexane/EtOAc 5:2). After completion of the photocatalytic reaction, the photocatalysts were separated by centrifugation at $10,000 \mathrm{rpm}$ rate. The quantitative value of benzaldehyde was obtained by column chromatography.

\section{Result and discussion}

\subsection{Complex compounds}

Quantum chemical modelling of the complexes. To reveal the structure and electronic properties of the isolated complexes I to III, we performed a DFT calculation of the molecular structure of both organic molecules: $\mathrm{HL}^{1}, \mathrm{HL}^{2}, \mathrm{HL}^{3}$, and molecules that model the structure of the isolated complexes: $\mathrm{Ti}\left(\mathrm{L}^{1}\right)_{2} \mathrm{OH}(\mathrm{I}), \mathrm{TiL}^{2}(\mathrm{OH})_{2}$ (II), $\mathrm{TiL}^{3}(\mathrm{OH})_{2}$ (III). The molecular structure of the calculated organic molecules and complexes is shown in Fig. 2 
(a)

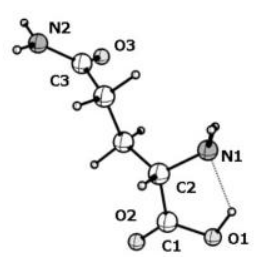

$\mathrm{HL}^{1}\left(\mathrm{a}_{1}\right)$

(b)

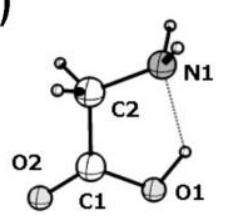

$\mathrm{HL}^{2}\left(\mathrm{~b}_{1}\right)$

(c)

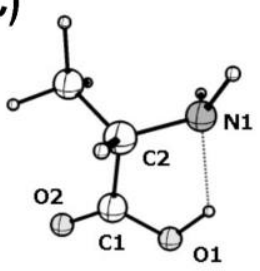

$\mathrm{HL}^{3}\left(\mathrm{c}_{1}\right)$

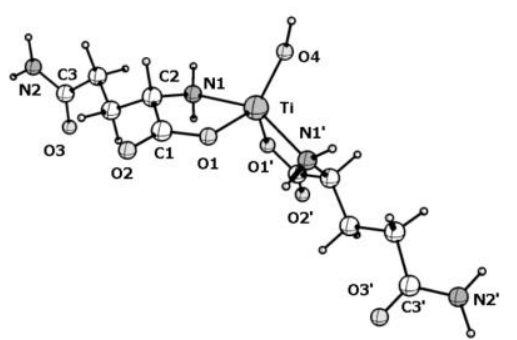

$\mathrm{Ti}\left(\mathrm{L}^{1}\right)_{2} \mathrm{OH}\left(\mathrm{a}_{2}\right)$

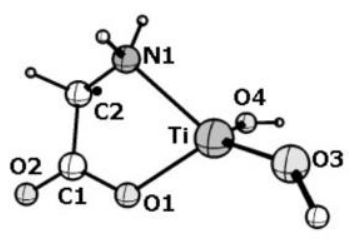

$\mathrm{TiL}^{2}(\mathrm{OH})_{2}\left(\mathrm{~b}_{2}\right)$

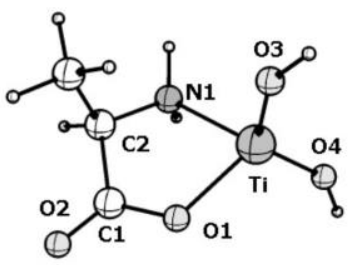

$\mathrm{TiL}^{3}(\mathrm{OH})_{2}\left(\mathrm{c}_{2}\right)$

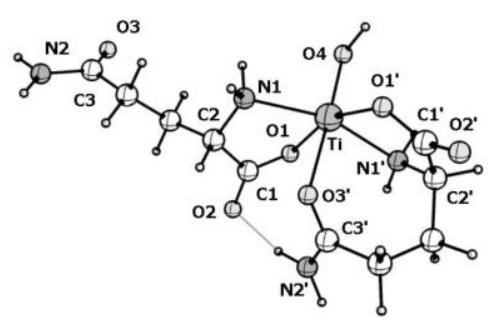

$\mathrm{Ti}\left(\mathrm{L}^{1}\right)_{2} \mathrm{OH} \quad\left(\mathrm{a}_{3}\right)$

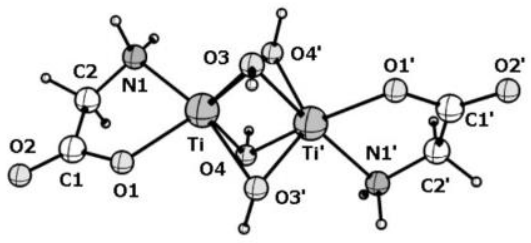

$\mathrm{Ti}_{2}\left(\mathrm{~L}^{2}\right)_{2}(\mathrm{OH})_{2}\left(\mathrm{~b}_{3}\right)$

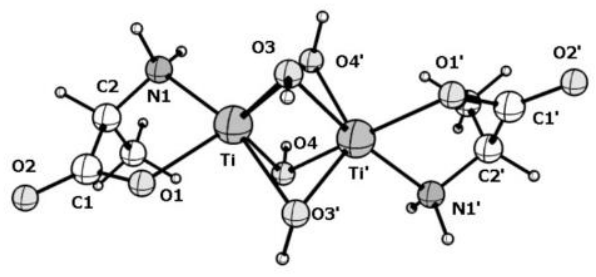

$\mathrm{Ti}_{2}\left(\mathrm{~L}^{2}\right)_{2}(\mathrm{OH})_{2}\left(\mathrm{c}_{3}\right)$

Fig. 2. The molecular structure of the molecules according to the calculation by the DFT method

Figure 2 shows the results of the calculation of organic molecules $\mathrm{HL}^{1}, \mathrm{HL}^{2}$, and $\mathrm{HL}^{3}$, which have an air force of $\mathrm{N} 2 \cdots \mathrm{H}(\mathrm{O} 1)$. Attempts to calculate the centre ion forms of $\mathrm{HL}^{2}$ molecules with the $\mathrm{BBC}(\mathrm{O} 1)-\cdots \mathrm{H}\left(\mathrm{NH}_{3}{ }^{+}\right)$showed less stability - during the calculation, the hydrogen atom passed from the nitrogen atom to the oxygen atom and we obtained the forms shown in Fig. 2. It should be noted that the organic molecules are stabilized by the BBC H(O1) $\cdots \mathrm{N} 1(\mathrm{R}=1,843-1,850 \AA)$.

The disadvantage of the $\mathrm{Ti}\left(\mathrm{L}^{1}\right)_{2} \mathrm{OH}\left(\mathrm{a}_{2}\right), \mathrm{TiL}^{2}(\mathrm{OH})_{2}\left(\mathrm{~b}_{2}\right)$ and $\mathrm{TiL}^{3}(\mathrm{OH})_{2}\left(\mathrm{c}_{2}\right)$ structures corresponding to the chemical analysis data is the low coordination numbers of titanium: five and four, instead of the expected coordination number six. It can be assumed that, in crystalline form, the titanium atom, being in forms $\left(a_{2}\right),\left(b_{2}\right)$, and $\left(c_{2}\right)$, can complete its coordination sphere due to the interaction with the oxygen atoms of neighbouring complex molecules, forming polymer structures. At the same time, the possibility of completing the coordination sphere of titanium in $\operatorname{Ti}\left(\mathrm{L}^{1}\right)_{2} \mathrm{OH}$ exists due to the additional interaction with the $\mathrm{O} 3$ atom of one of the ligand molecules, as in the $\mathrm{Ti}\left(\mathrm{L}^{1}\right)_{2} \mathrm{OH}\left(\mathrm{a}_{3}\right)$ molecule (Fig. 2). It was found that the $\operatorname{Ti}\left(\mathrm{L}^{1}\right)_{2} \mathrm{OH}\left(\mathrm{a}_{3}\right)$ form is $60 \mathrm{~kJ} / \mathrm{mol}$ more stable than the $\mathrm{Ti}\left(\mathrm{L}^{1}\right)_{2} \mathrm{OH}\left(\mathrm{a}_{2}\right)$ form. 
In the case of $\mathrm{TiL}^{2}(\mathrm{OH})_{2}$ and $\mathrm{TiL}^{3}(\mathrm{OH})_{2}$ complexes, the possibility of completing the coordination sphere of titanium is possible, for example, in the dimer molecules $\operatorname{TiL}^{2}(\mathrm{OH})_{2}$ $\left(b_{3}\right)$ and $\mathrm{TiL}^{3}(\mathrm{OH})_{2}\left(\mathrm{c}_{3}\right)$ (Fig. 2). It was found that for these molecules the energy of structures $\left(b_{3}\right)$ and $\left(c_{3}\right)$ are 134 and $135 \mathrm{~kJ} /$ moles lower than the doubled energies of structures $\left(b_{2}\right)$ and $\left(\mathrm{c}_{2}\right)$, respectively. The results obtained for $\mathrm{Ti}\left(\mathrm{L}^{1}\right)_{2} \mathrm{OH}$, $\mathrm{TiL}^{2}(\mathrm{OH})_{2}$, and $\mathrm{TiL}^{3}(\mathrm{OH})_{2}$ indicate higher stability of titanium octahedral complexes in comparison with tetragonal pyramidal or tetrahedral ones.

Some calculated bond lengths and bond angles for organic molecules and complexes are shown in Table 1.

Table 1. The lengths of some bonds R $(\AA)$ calculated by the DFT method and the bond angles $\omega$ (deg) in the molecules (The numbering of atoms is given in Fig. 2.)

\begin{tabular}{cccccccccc}
\hline Molecule & $\mathbf{H L}^{\mathbf{1}}$ & $\mathbf{I}(\mathbf{a})$ & $\mathbf{I}(\mathbf{b})$ & $\mathbf{H L}^{\mathbf{2}}$ & $\mathbf{I I}(\mathbf{a})$ & $\mathbf{I I}(\mathbf{b})$ & $\mathbf{H L}^{\mathbf{3}}$ & $\mathbf{I I I}(\mathbf{a})$ & $\mathbf{I I I}(\mathbf{b})$ \\
\hline Bond & $\boldsymbol{R}(\mathbf{A})$ & & & & & & & & \\
Ti-O1 & - & 1,966 & 2,049 & - & 1,975 & 1,985 & - & 1,976 & 1,984 \\
Ti-N1 & - & 2,221 & 2,247 & - & 2,223 & 2,228 & - & 2,214 & 2,223 \\
Ti-O3 & - & - & - & - & 1,813 & 1,951 & - & 1,817 & 1,949 \\
Ti- O3' & - & - & 2,241 & - & - & 2,141 & - & - & 2,154 \\
Ti-O4 & - & 1,812 & 1,832 & - & 1,817 & 2,017 & - & 1,813 & 2,019 \\
Ti-O4' & - & - & - & - & - & 2,202 & - & - & 2,199 \\
O1-H & 0,997 & - & - & 0,999 & - & - & 0,997 & - & - \\
C1-O1 & 1,334 & 1,314 & 1,286 & 1,333 & 1,309 & 1,310 & 1,335 & 1,307 & 1,310 \\
C1-O2 & 1,203 & 1,209 & 1,230 & 1,202 & 1,209 & 1,209 & 1,203 & 1,211 & 1,210 \\
C1-C2 & 1,549 & 1,555 & 1,547 & 1,544 & 1,547 & 1,549 & 1,548 & 1,555 & 1,553 \\
C2-N1 & 1,470 & 1,483 & 1,485 & 1,467 & 1,486 & 1,486 & 1,471 & 1,493 & 1,493 \\
C3-O3 & 1,217 & 1,216 & 1,216 & - & - & - & - & - & - \\
C3-N2 & 1,365 & 1,366 & 1,366 & - & - & - & - & - & - \\
C3'-O3 & & & 1,246 & - & - & - & - & - & - \\
C3'-N2' & & & 1,338 & - & - & - & - & - & - \\
& & & & & & & & & \\
Angle & $\boldsymbol{\omega}$ & $(\mathbf{D e g r e e})$ & & & & & & 77 & 78 \\
O1TiN1 & - & 77 & 75 & - & 77 & 78 & - & -123 & 122 \\
TiO1C1 & - & 124 & 116 & - & 124 & 122 & - & 107 & 107 \\
TiN1C2 & - & 110 & 109 & - & 107 & 106 & - & 113 & 114 \\
O1C1C2 & 113 & 114 & 116 & 113 & 113 & 113 & 113 & 113 \\
C1C2N1 & 110 & 109 & 110 & 111 & 110 & 110 & 108 & 108 & 109 \\
O3TiO4 & - & - & - & - & 125 & 121 & - & 125 & 121 \\
\hline
\end{tabular}

From the results given in table 1, it follows that the five-membered metal cycles in the complexes $\operatorname{Ti}\left(\mathrm{L}^{1}\right)_{2} \mathrm{OH}$, $\operatorname{TiL}^{2}(\mathrm{OH})_{2}$, and $\mathrm{TiL}^{3}(\mathrm{OH})_{2}$ have a similar structure, and the bond lengths naturally change upon transition from organic molecules to complexes. Complex I $\left(a_{3}\right)$ somewhat falls out of the range of bond lengths and bond angles, where the Ti-O1 and Ti-N1 bonds are longer than in other complexes, the angle O1TiN1 is smaller (Table 1). A 
similar difference is associated with the restructuring of the coordination polyhedron. Besides, the $\mathrm{C} 1-\mathrm{O} 2$ bond in this complex is slightly longer than in the other molecules, due to the participation of the $\mathrm{O} 2$ atom in the formation of the $\mathrm{H}\left(\mathrm{N} 2^{\prime}\right)^{\prime} \cdots \mathrm{O} 2$ air force $(\mathrm{R}=1.860$ $\AA$ A), which additionally stabilizes the molecule.

Dimeric molecules $\left(a_{3}, b_{3}\right.$, and $\left.c_{3}\right)$ can be formed by the approach of molecules $\left(a_{2}, b_{2}\right.$, and $c_{2}$ ), in which the planes of the metallocycles are approximately perpendicular and the oxygen atoms of the hydroxyl groups form a distorted square structure. However, complete alignment of $\mathrm{Ti}-\mathrm{O}$ bonds do not occur. Thus, the bonds $\mathrm{Ti}-\mathrm{O} 3$ and $\mathrm{Ti}-\mathrm{O} 4$ are shorter than the bonds Ti-O3 'and Ti-O4' (Table 1). Similarly, Ti'-O3 'and Ti'-O4' bonds are shorter than Ti'-O3 and Ti'-O4 bonds. Note that the $\mathrm{Ti}-\mathrm{Ti}$ 'distances in the dimeric complexes II $\left(\mathrm{b}_{3}\right)$ and III $\left(\mathrm{c}_{3}\right)$ are 2.307 and $2.310 \AA$, respectively. The atomic charges calculated by the NBO method in the calculated molecules are shown in Table 2.

Table 2. The charges calculated by the NBO method on some atoms in the molecules (The numbering of atoms is given in Fig. 2.)

\begin{tabular}{|c|c|c|c|c|c|c|c|c|c|}
\hline Atom & $\mathrm{HL}^{1}$ & I (a) & I (a3) & $\mathrm{HL}^{2}$ & II $\left(\mathbf{b}_{2}\right)$ & II (b) & $\mathrm{HL}^{3}$ & III $\left(c_{2}\right)$ & III $\left(\mathbf{c}_{3}\right)$ \\
\hline $\mathrm{Ti}$ & - & $+1,543$ & $+1,542$ & - & $+1,564$ & $+1,421$ & - & $+1,563$ & $+1,437$ \\
\hline $\mathrm{H}(\mathrm{O} 1)$ & $+0,491$ & - & - & $+0,488$ & - & - & $-0,491$ & - & \\
\hline $\mathrm{O} 1$ & $-0,698$ & $-0,797$ & $-0,777$ & $-0,702$ & $-0,795$ & $-0,756$ & $-0,700$ & $-0,790$ & $-0,762$ \\
\hline $\mathrm{O} 2$ & $-0,605$ & $-0,613$ & $-0,702$ & $-0,604$ & $-0,614$ & $-0,609$ & $-0,604$ & $-0,621$ & $-0,613$ \\
\hline $\mathrm{O} 3$ & $-0,636$ & $-0,631$ & $-0,634$ & - & $-0,976$ & $-0,925$ & - & $-0,974$ & $-0,927$ \\
\hline O3' & - & $-0,633$ & $-0,729$ & - & - & $-0,927$ & - & - & $-0,928$ \\
\hline $\mathrm{O} 4$ & - & $-0,956$ & $-0,922$ & - & $-0,974$ & $-0,947$ & - & $-0,976$ & $-0,947$ \\
\hline O4' & & & & & & $-0,957$ & & & $-0,958$ \\
\hline N1 & $-0,892$ & $-0,884$ & $-0,879$ & $-0,894$ & $-0,895$ & $-0,884$ & $-0,888$ & $-0,892$ & $-0,888$ \\
\hline $\mathrm{N} 2$ & $-0,809$ & $-0,811$ & $-0,811$ & - & - & - & - & - & - \\
\hline $\mathrm{C} 1$ & $+0,848$ & $+0,852$ & $+0,863$ & $+0,833$ & $+0,829$ & $+0,826$ & $+0,840$ & $+0,838$ & $+0,834$ \\
\hline $\mathrm{C} 2$ & $-0,136$ & $-0,130$ & $-0,122$ & $-0,318$ & $-0,309$ & $-0,307$ & $-0,139$ & $-0,135$ & $-0,128$ \\
\hline C3 & $+0,721$ & $-0,721$ & $+0,720$ & - & - & - & - & - & - \\
\hline
\end{tabular}

The calculated charges of titanium atoms in the complexes range from +1.421 to +1.564 (Table 2). These values differ significantly from those assumed in the case of ionic bonding of charges on the titanium atom +3 . The magnitude of the charge of the titanium atom indicates a significant contribution of the covalent component in the interaction of titanium with ligands and transfer of about 1.5 electrons from the ligands to each titanium ion. In this case, each organic molecule passes from 0.45 to 0.50 electrons, and each hydroxide ion from 0.50 to 0.54 electrons. The populations of titanium valence orbitals have the following meanings: 
In $\left.\operatorname{Ti}\left(\mathrm{L}^{1}\right)_{2} \mathrm{OH}\right) \mathrm{I}\left(\mathrm{a}_{2}\right) 3 d^{2.23} 4 s^{0.19} 4 p^{0.01} 4 d^{0.04}$, In Ti( $\left.\left.\mathrm{L}^{1}\right)_{2} \mathrm{OH}\right) \mathrm{I}\left(\mathrm{a}_{3}\right) 3 d^{2,20} 4 s^{0.21} 4 p^{0.01} 4 d^{0.04}$, In $\operatorname{TiL}^{2}(\mathrm{OH})_{2} \operatorname{II}\left(\mathrm{b}_{2}\right) 3 d^{2.21} 4 s^{0.19} 4 p^{0.03} 4 d^{0.03}$, In $\mathrm{TiL}^{2}(\mathrm{OH})_{2} \mathrm{II}\left(\mathrm{b}_{3}\right) 3 d^{2.31} 4 s^{0.22} 4 p^{0.02} 4 d^{0.05}$, In $\operatorname{TiL}^{3}(\mathrm{OH})_{2} \operatorname{III}\left(\mathrm{c}_{2}\right) 3 d^{2.21} 4 s^{0.19} 4 p^{0.03} 4 d^{0.03}$, $\operatorname{In~TiL}^{3}(\mathrm{OH})_{2} \operatorname{III}\left(\mathrm{c}_{3}\right) 3 d^{2.30} 4 s^{0.23} 4 p^{0.02} 4 d^{0.04}$.

It can be seen that mainly $3 \mathrm{~d}$ orbitals are populated in the complexes at the titanium atom.

The transfer of electron density from ligands to titanium atoms occurs so that the electron density on the $\mathrm{O} 1$ and $\mathrm{N} 1$ atoms directly bonded to the titanium atom, as a rule, changes little and even increases, and on atoms that are not directly bonded to the titanium atom, decreases. In this case, the electron density on the $\mathrm{O} 1$ atom increases especially: charges on this atom lie in the range from -0.698 to -0.702 in organic molecules and -0.756 to -0.797 in complexes. Note that the released charge on the $\mathrm{O} 2$ atom in the $\mathrm{Ti}\left(\mathrm{L}^{1}\right)_{2} \mathrm{OH}(\mathrm{I})$ (b) complex is due to the presence of the $\mathrm{H}\left(\mathrm{N} 2{ }^{\prime}\right) \cdots \mathrm{O} 2$ air force.

FT-IR spectroscopy and elemental analysis. The FT-IR spectroscopy of the complex compounds of titanium (III) with Glutamine $\left(\mathrm{L}^{1}\right)$, Glycine $\left(\mathrm{L}^{2}\right)$, and L-Alanine $\left(\mathrm{L}^{3}\right)$ and their characterizations are illustrated in figures 3-5.

Initially, the ligands are investigated in the free mode. There are different peaks in the free amino acids' derivatives. However, some of them have been recognized as the main functional groups of the amino acids. There are small differences between $\beta$-amino acids (Lalanine and glutamine) and $\alpha$-amino acid (Glycine). In both cases, there is a sharp peak at around $2130 \mathrm{~cm}^{-1}$, which related to $\mathrm{N}-\mathrm{H}$ stretching in $\mathrm{NH}^{3+}$ group[43]. The peaks between 1640 and $1610 \mathrm{~cm}^{-1}$ are related to the deformation of $\mathrm{NH}^{3+}$. There is another peak related to the ionic carboxyl group (around $1410 \mathrm{~cm}^{-1}$ ). However, this is hard to see compared to other peaks. Also, $\mathrm{COO}^{-}$mode is observable near $1600 \mathrm{~cm}$. Furthermore and according to some kinds of literature, ammonium can be seen at $2600 \mathrm{~cm}^{-1}$ [44]. The main difference between glycine, as $\alpha$-amino acid, and $\beta$-amino acids (L-alanine and glutamine) is a broad carboxyl peak in near $1600 \mathrm{~cm}^{-1}$

After coordination of the metal ion, there are some changes, which effected on the vibration energy of some of the mentioned peaks. In the case $\mathrm{L}^{1}+\mathrm{Ti}$ (Glutamine complex) (Fig.3), both peaks corresponding to the stretching carboxylate group and stretching vibrations of ammonium reduced to around 1632 and $2038 \mathrm{~cm}^{-1}$ from 1638 and $2043 \mathrm{~cm}^{-1}$ respectively. Also, the peak related to the ionic carboxyl group was reduced from 1415 to 
$1410 \mathrm{~cm}^{-1}$. Such this change may be justified by $\eta$-mode coordination of titanium ion to the resonance forms of the carboxylate group.

In the next case, $\mathrm{L}^{2}+\mathrm{Ti}$ (Glycine complex) (Fig. 4), there is a huge reduction in ammonium peak, and it changed from 2213 to $2136 \mathrm{~cm}^{-1}$. Also, the carboxylate peak was deformed after complexation. Also, a new peak at around $3440 \mathrm{~cm}^{-1}$ badges of intermolecular bond in $\mathrm{O}-\mathrm{H}$ stretching.

In the last case, $\mathrm{L}^{3}+\mathrm{Ti}$ (L-Alanine) had its unique effect on the metal ion (Fig. 5). The significant change occurred in the carboxylic acid (O-H stretching), which reduced the peak from the around 2742 to $2729 \mathrm{~cm}^{-1}$. Also, the peak related to ammonium changed and raised to around $2615 \mathrm{~cm}^{-1}$ from around $2600 \mathrm{~cm}^{-1}$.

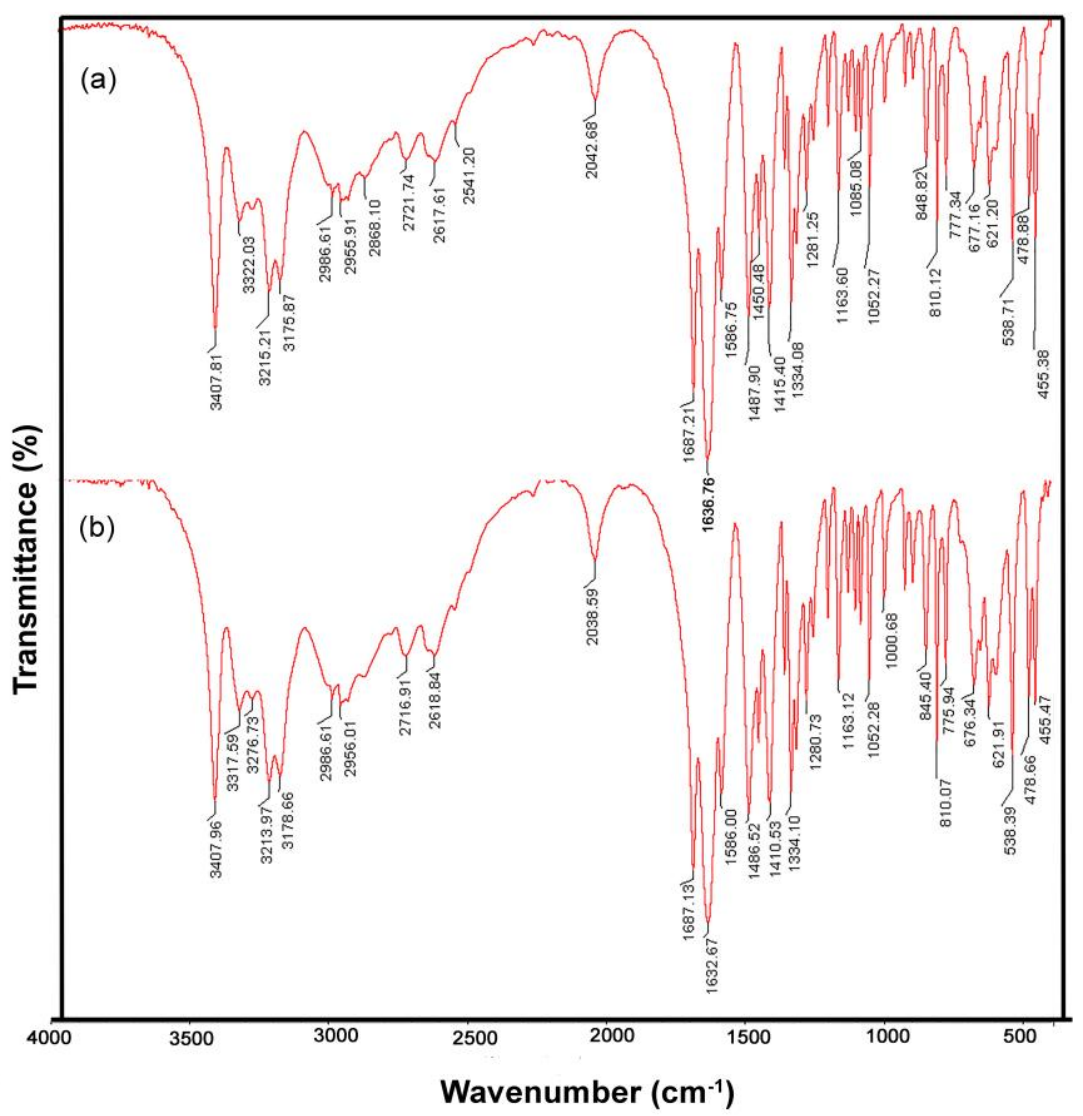

Fig. 3. IR spectroscopy of (a) glutamine $\left(\mathrm{L}^{1}\right)$, and (b) glutamine with titanium chloride (III) $\left(\mathrm{L}^{1}+\mathrm{Ti}\right)$ 


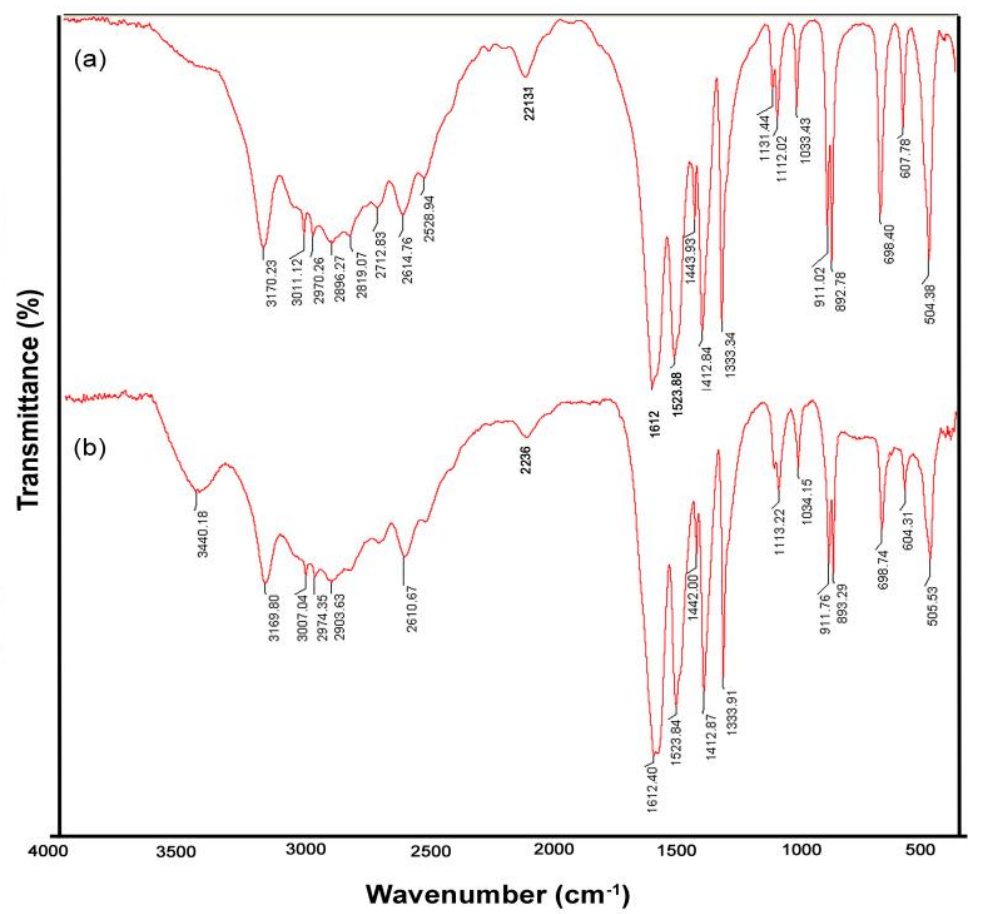

Fig. 4. IR spectroscopy of (a) glycine $\left(\mathrm{L}^{2}\right)$, and (b) glycine with titanium chloride (III) $\left(\mathrm{L}^{2}+\mathrm{Ti}\right)$

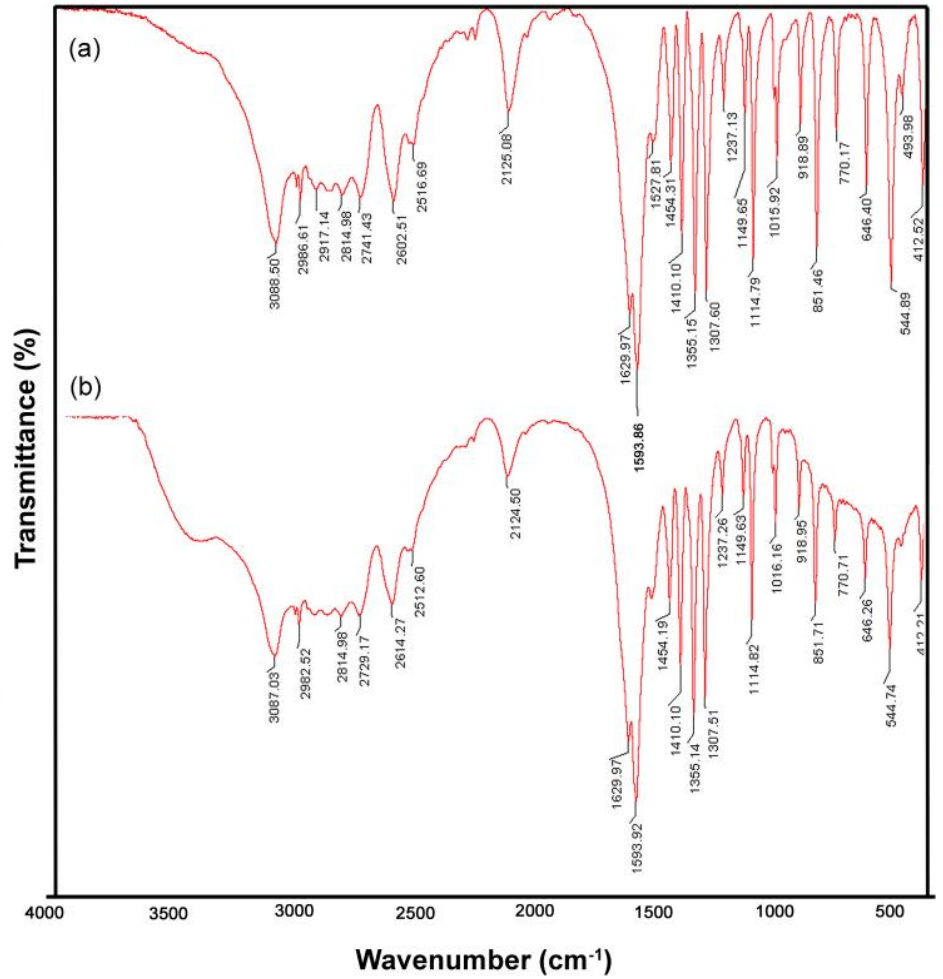

Fig. 5. IR spectroscopy of (a) L-Alanine ( $\left.\mathrm{L}^{3}\right)$, and (b) L-Alanine with titanium chloride (III) 
Elemental analysis of the complexes was taken in table 3.

Table 3. Elemental analysis of the complexes compounds

\begin{tabular}{lcccccc}
\hline Name & Formula & $\mathbf{C}[\%]$ & $\mathbf{H}[\%]$ & $\mathbf{N}[\%]$ & $\mathbf{O}[\%]$ & Ti[\%] \\
\hline & & $\mathrm{C} / \mathrm{O}$ & $\mathrm{C} / \mathrm{O}$ & $\mathrm{C} / \mathrm{O}$ & $\mathrm{C} / \mathrm{O}$ & $\mathrm{C} / \mathrm{O}$ \\
$\mathrm{Ti}\left(\mathrm{L}^{1}\right)_{2} \mathrm{OH}$ & $\mathrm{C}_{10} \mathrm{H}_{16} \mathrm{~N}_{4} \mathrm{O}_{6} \mathrm{Ti}$ & $35.73 / 36.42$ & $4.8 / 5.93$ & $16.67 / 14.42$ & $28.56 / 27.32$ & $4.24 / 13.21$ \\
$\mathrm{Ti} \mathrm{L}^{2}(\mathrm{OH})_{2}$ & $\mathrm{C}_{4} \mathrm{H}_{10} \mathrm{~N}_{2} \mathrm{O}_{8} \mathrm{Ti}_{2} 2$ & $15.50 / 15.99$ & $3.25 / 3.61$ & $9.04 / 8.96$ & $11.31 / 40.32$ & $0.90 / 29.38$ \\
$\mathrm{Ti} \mathrm{L}{ }^{3}(\mathrm{OH})_{2}$ & $\mathrm{C}_{6} \mathrm{H}_{14} \mathrm{~N}_{2} \mathrm{O}_{8} \mathrm{Ti}_{2}$ & $21.33 / 22.18$ & $4.18 / 4.52$ & $8.29 / 7.42$ & $37.88 / 36.98$ & $8.33 / 27.87$ \\
C: Calculated & & & & & & \\
O: Obtained & & & & & &
\end{tabular}

\subsection{Nanoparticles}

The obtained nanoparticles were labelled as followings; $\mathrm{TiO}_{2}(\mathrm{~A}), \mathrm{TiO}_{2}(\mathrm{R}), \mathrm{TiO}_{2}$ $\left(\mathrm{A}_{0.2} \mathrm{R}_{0.8}\right)$, and $\mathrm{TiO}_{2}\left(\mathrm{~A}_{0.6} \mathrm{~B}_{0.4}\right)$.

XRD pattern. The XRD pattern of the obtained nanoparticles was carried out between 10 and 80 degrees $(10<2 \theta<80)$.

The results show that all the nanoparticles are in good crystallinity with their strong and tiny diffraction peaks and different phases and structures related to $\mathrm{TiO}_{2}$ nanoparticle were obtained at different temperatures.

According to the result, the sample with the XRD pattern provided in figure $6 \mathrm{a}\left(\mathrm{A}_{0.2} \mathrm{R}_{0.8}\right)$ has been obtained as a mix of anatase (JCPDS No.21e1272) and rutile (JCPDS NO. 21e1276) phases, and the main peaks were placed at 25.2558, 27.4214, 37.7254, 41.2115, 47.9888 and 53.7981 .

$\mathrm{TiO}_{2}\left(\mathrm{~A}_{0.6} \mathrm{~B}_{0.4}\right)$ is illustrated by figure $6 \mathrm{~b}$. The main peaks were located at 25.2558 , 27.4214, 32.84, 36.13, 47.89, 54.37, and 62.8. According to the result, it is matched with JCPDS 76-1934.

Anatase phase, as the first phase of $\mathrm{TiO}_{2}$, was obtained at around $525^{\circ} \mathrm{C}$ (Fig. $6 \mathrm{c}$ ). The main peaks are observable at 25.3192, 37.87, 48.16, 54.01, 55.20, 62.87, 68.92, and 70.48. JCPDS No. $21 \mathrm{e} 1272$ is the best match with the obtained sample, which proved $100 \%$ Anatase phase.

Finally, the rutile phase, as the most stable and last phase of $\mathrm{TiO}_{2}$, is illustrated by figure $6 \mathrm{~d}$. This phase, the same as other structures, was obtained at high purity. The main peaks are located at 27.49, 36.13, 39.24, 41.28, 44.09, 54.37, 56.67, 62.08, 64.08. According to the result, the obtained sample is a 100\% rutile phase with JCPDS NO. 21e1276. 
The average crystallite diameter (D) of the obtained nanoparticles and their lattice strain calculated in the diffraction pattern. Scherer equation (1) was used to calculate the mentioned parameters and the data are taken in table 4.

$$
\mathrm{D}_{\mathrm{c}}=\mathrm{k} \lambda / \beta \cos \theta
$$

Where, $\mathrm{K}$ is shape factor (about 0.9$), \lambda$ is the wavelength of the $\mathrm{X}$-ray source $(1.5406 \AA$ ), $\beta$ is the breadth of the observed diffraction line at its half intensity maximum (400).

Table 4. Chemical-physical features of $\mathrm{TiO}_{2}$

\begin{tabular}{lc}
\hline \multicolumn{1}{c}{ Sample } & $\begin{array}{c}\text { Crystallite size } \\
\text { (nm) }\end{array}$ \\
\hline $\mathrm{TiO}_{2}\left(\mathrm{~A}_{0.2} \mathrm{R}_{0.8}\right)$ & 25,51 \\
$\mathrm{TiO}_{2}\left(\mathrm{~A}_{0.6} \mathrm{R}_{0.4}\right)$ & 17,87 \\
$\mathrm{TiO}_{2}(\mathrm{~A})$ & 31,95 \\
$\mathrm{TiO}_{2}(\mathrm{R})$ & 34,54 \\
\hline
\end{tabular}
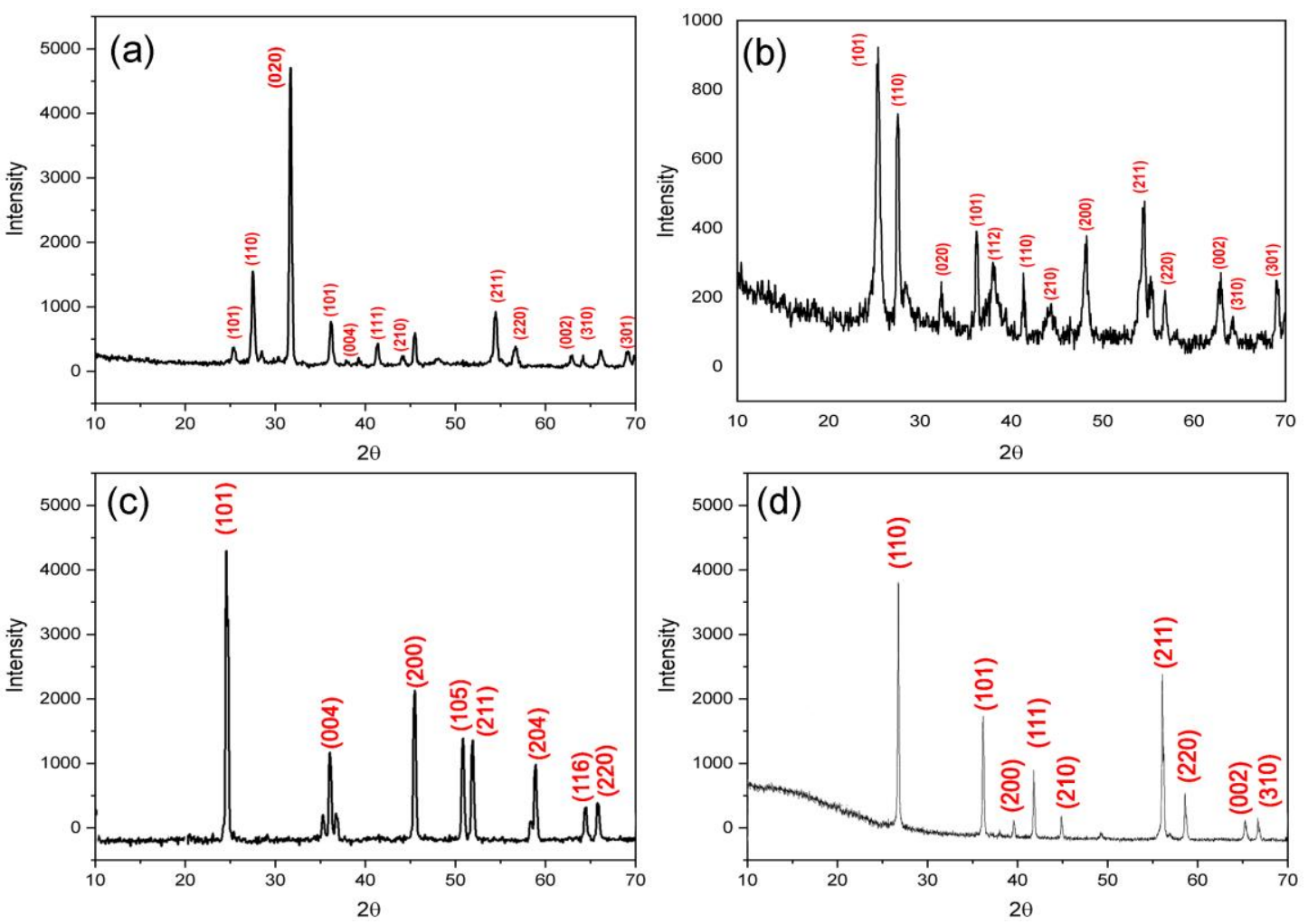

Fig. 6. $\mathrm{XRD}$ pattern of (a) $\mathrm{TiO}_{2}\left(\mathrm{~A}_{0.2} \mathrm{R}_{0.8}\right)$, (b) $\mathrm{TiO}_{2}\left(\mathrm{~A}_{0.6} \mathrm{R}_{0.4}\right)$, (c) $\mathrm{TiO}_{2}(\mathrm{~A})$, and (d) $\mathrm{TiO}_{2}(\mathrm{R})$

FT-IR spectroscopy. Investigation of the surface state of prepared nanoparticle was carried out by FT-IR spectrum, adjusted between $400-4000 \mathrm{~cm}^{-1}$ (Fig. 7).

There is a broad absorption band between 3400 and $3500 \mathrm{~cm}^{-1}$, which related to the absorption of the $\mathrm{H}_{2} \mathrm{O}$ molecules' stretch on the surface of the $\mathrm{TiO}_{2}$ samples. It is clear in the cases $\mathrm{A}_{0.6} \mathrm{R}_{0.4}$ and $\mathrm{R}$ [45]. Besides, some components band gap illustrates various kind of 
interaction of water molecules with $\mathrm{TiO}_{2}$, containing their absorption into the mesoporous [46]. The broad absorption band between 400 and $800 \mathrm{~cm}^{-1}$ and the maximum at around 1000 $\mathrm{cm}^{-1}$ corresponding to Ti-O stretches in $\mathrm{TiO}_{6}$ octahedral of different types of distortion. Some adsorptions with very low intensity, around $1300 \mathrm{~cm}^{-1}$, show the presence of $\mathrm{CO}_{2}$, which exist in the air and absorbed by the surface of the $\mathrm{TiO}_{2}$ nanoparticles.

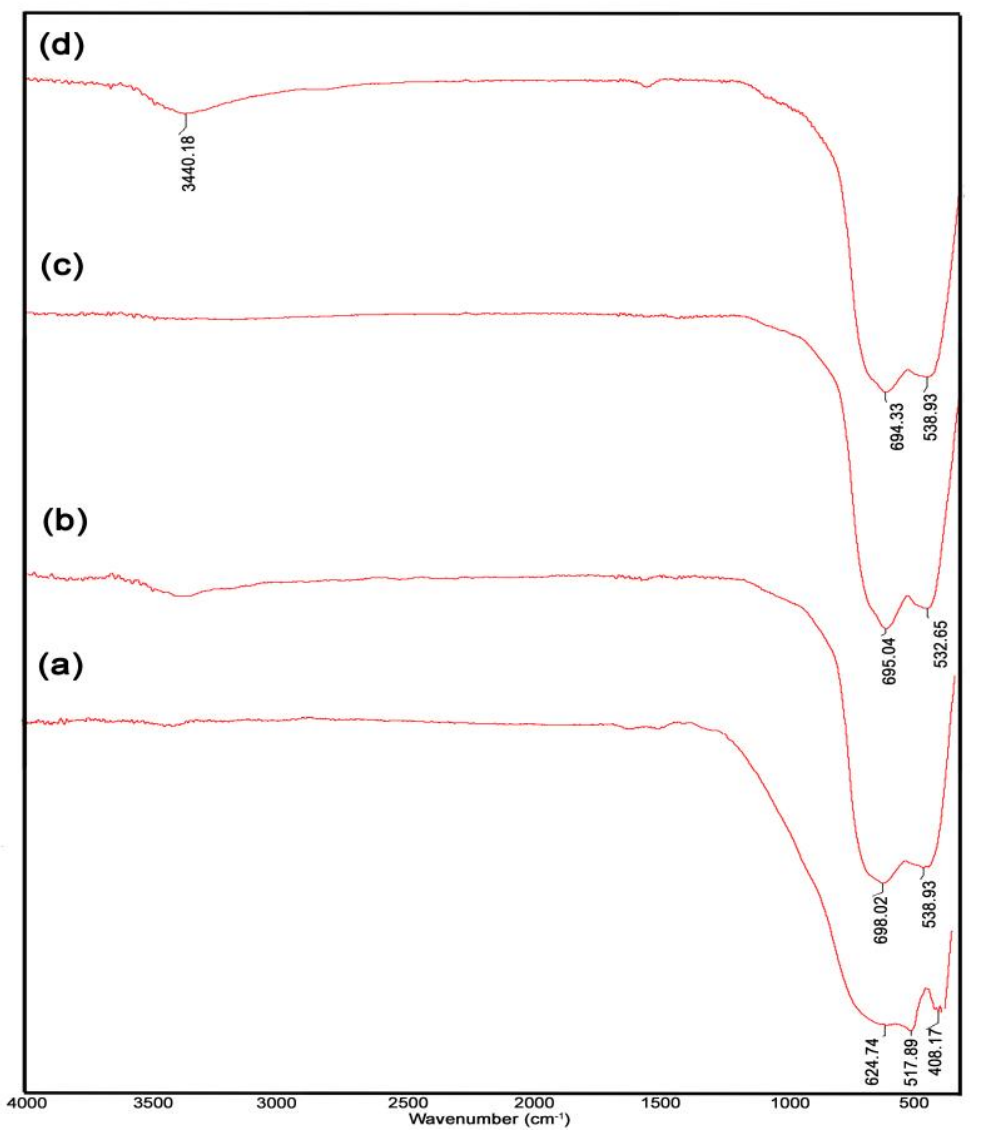

Fig. 7. FT-IR spectroscopy of the nanoparticles; (a) $\mathrm{TiO}_{2}\left(\mathrm{~A}_{0.2} \mathrm{R}_{0.8}\right)$, (b) $\mathrm{TiO}_{2}\left(\mathrm{~A}_{0.6} \mathrm{R}_{0.4}\right)$ (c) $\mathrm{TiO}_{2}(\mathrm{~A})$, and (d) $\mathrm{TiO}_{2}(\mathrm{R})$

FESEM and EDX analysis. Because each crystal facet provides especial properties so the morphology of the obtained nanoparticles was investigated by FESEM image (Fig.8). All the nanoparticles were obtained in very high purity, as they are seen in the figures. This is one of the most important properties of the oxide nanoparticles, which synthesized through organometallic complex compounds[47].

There are very uniform in their surface and the shapes of the nanoparticles have been investigated by TEM image. There is no accumulation and tendency, which almost always is due to the high temperature and stability of the nanoparticles. Also, the high porosity on the surface of the samples made them be used as good photocatalysts for radicalism reactions.

The obtained size for all the nanoparticles was calculated; mean size for $\mathrm{TiO}_{2}\left(\mathrm{~A}_{0.2} \mathrm{R}_{0.8}\right)$ 
structure was around $25 \mathrm{~nm}$, and for $\mathrm{TiO}_{2}\left(\mathrm{~A}_{0.6} \mathrm{R}_{0.4}\right)$, anatase, and rutile was around $20 \mathrm{~nm}$, $29 \mathrm{~nm}$ and $31 \mathrm{~nm}$ respectively. The results obtained from the FESEM were well equal to what obtained from the XRD analysis.

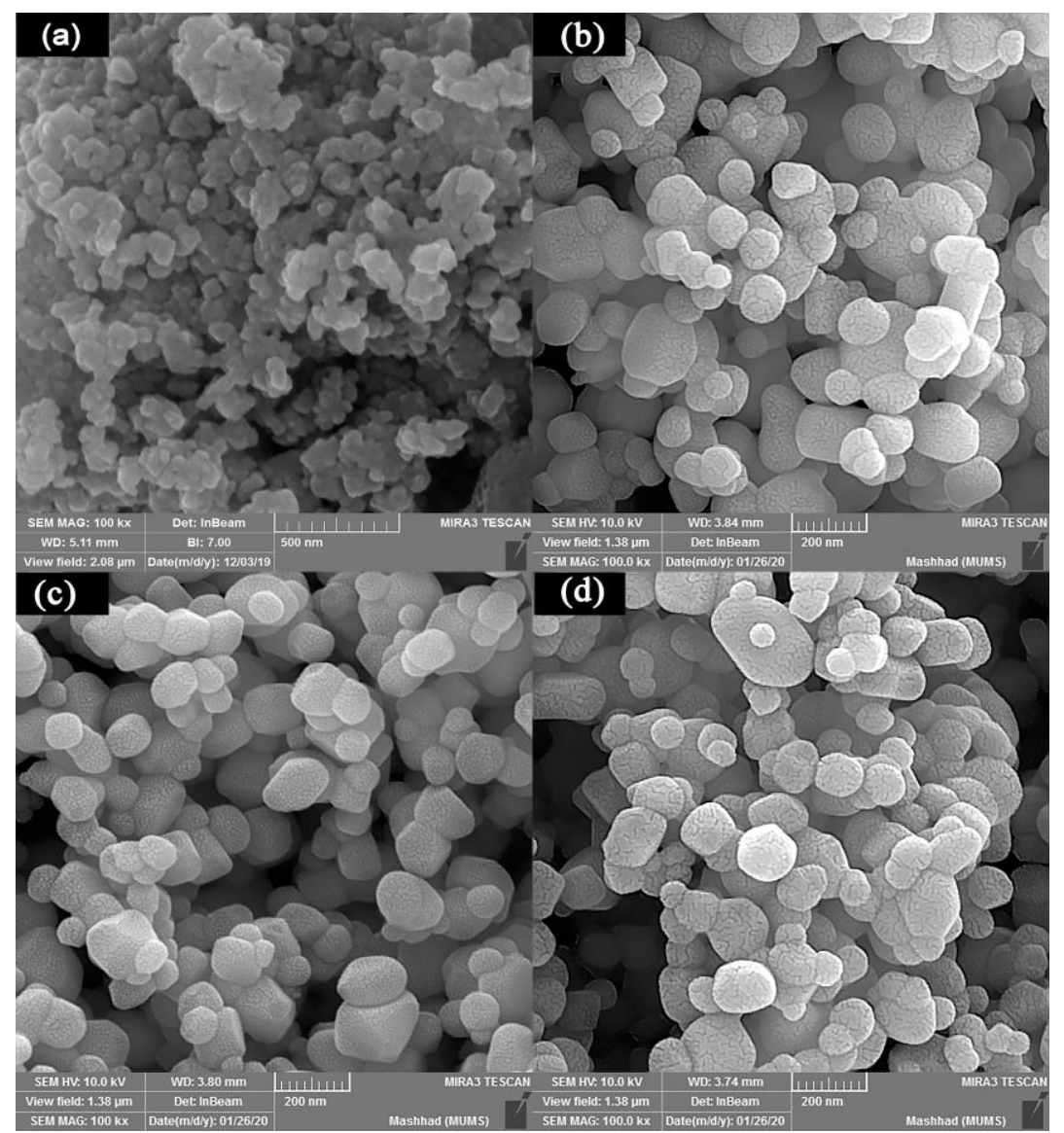

Fig. 8. FESEM image of (a) $\mathrm{TiO}_{2}\left(\mathrm{~A}_{0.2} \mathrm{R}_{0.8}\right)$, (b) $\mathrm{TiO}_{2}\left(\mathrm{~A}_{0.6} \mathrm{R}_{0.4}\right)$, (c) $\mathrm{TiO}_{2}(\mathrm{~A})$, and (d) $\mathrm{TiO}_{2}(\mathrm{R})$

Besides, EDX of the nanoparticles, to investigate the amount of the elements was carried out (Fig. 9). According to the analysis, all the nanoparticles were synthesized with high purity (Table 5).

Table 5. Elemental analysis of the samples

\begin{tabular}{lll}
\hline Sample & Ti [\%] & O[\%] \\
\hline $\mathrm{TiO}_{2}\left(\mathrm{~A}_{0.2} \mathrm{R}_{0.8}\right)$ & 54.45 & 45.55 \\
$\mathrm{TiO}_{2}\left(\mathrm{~A}_{0.6} \mathrm{R}_{0.4}\right)$ & 50.10 & 49.90 \\
$\mathrm{TiO}_{2}(\mathrm{~A})$ & 51.31 & 48.69 \\
$\mathrm{TiO}_{2}(\mathrm{R})$ & 50.03 & 49.97 \\
\hline
\end{tabular}



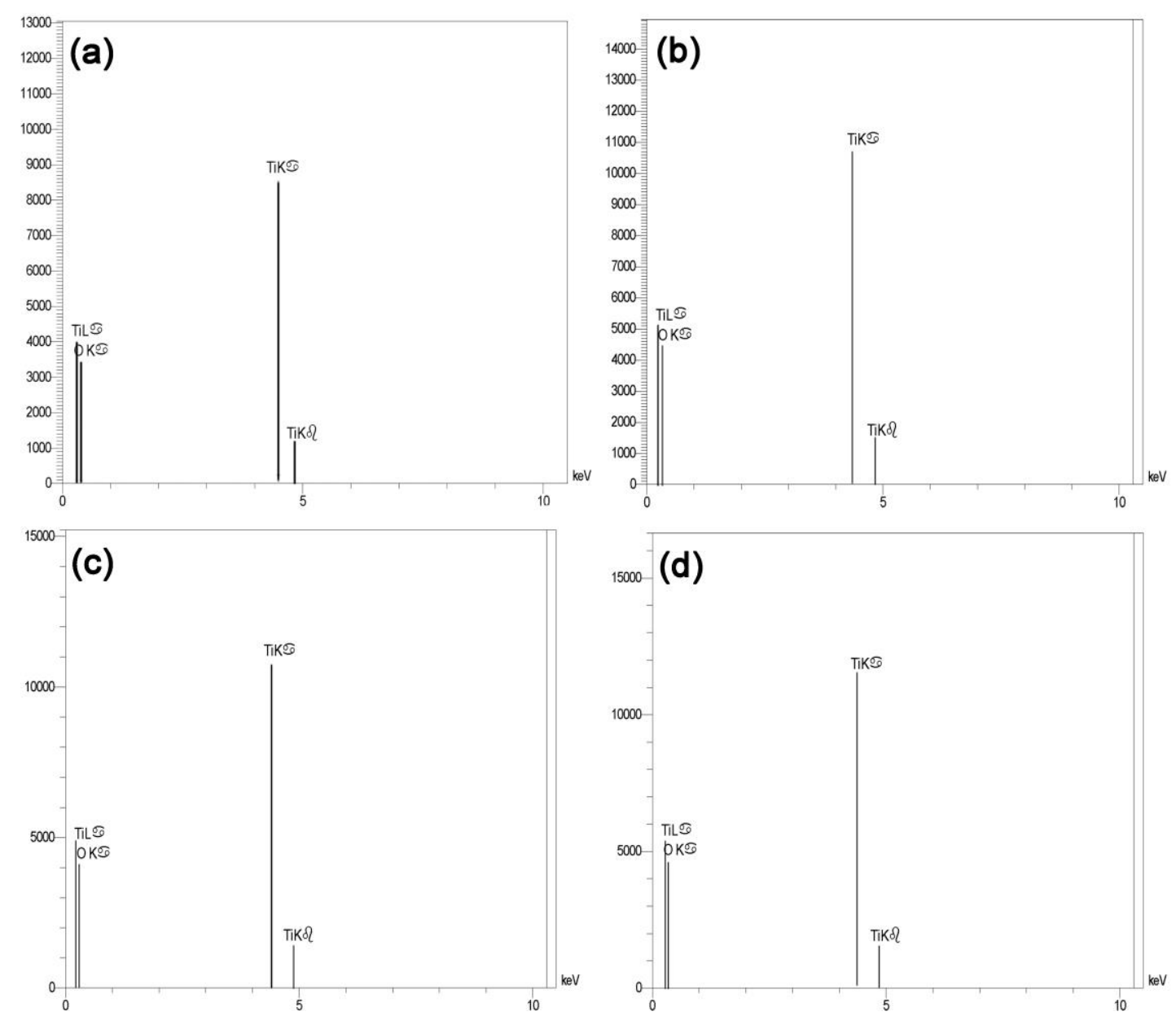

Fig. 9. EDX pattern of (a) $\mathrm{TiO}_{2}\left(\mathrm{~A}_{0.2} \mathrm{R}_{0.8}\right)$, (b) $\mathrm{TiO}_{2}\left(\mathrm{~A}_{0.6} \mathrm{R}_{0.4}\right)$, (c) $\mathrm{TiO}_{2}(\mathrm{~A})$, and (d) $\mathrm{TiO}_{2}(\mathrm{R})$

TEM analysis. To further investigation of the obtained nanoparticle TEM image analysis was carried out (Fig.10).

Figure 10a shows the TEM image of the $\mathrm{TiO}_{2}\left(\mathrm{~A}_{0.2} \mathrm{R}_{0.8}\right)$ structure. According to the analysis, the anatase and rutile phases grew on different nuclei during the process. Indeed, the anatase and rutile phases appeared nearby. During the process of the formation of $\mathrm{TiO}_{2}$ $\left(\mathrm{A}_{0.2} \mathrm{R}_{0.8}\right)$ structure, rutile phase forms an over-layer on the anatase surface.

$\mathrm{TiO}_{2}\left(\mathrm{~A}_{0.6} \mathrm{R}_{0.4}\right)$ structure is illustrated in figure $10 \mathrm{~b}$. Controlling conditions to $\mathrm{TiO}_{2}$ $\left(\mathrm{A}_{0.6} \mathrm{R}_{0.4}\right)$ structure is more difficult than anatase and rutile, even $\mathrm{TiO}_{2}\left(\mathrm{~A}_{0.2} \mathrm{R}_{0.8}\right)$ structure, if it is expected just to synthesis a single structure of $\mathrm{TiO}_{2}\left(\mathrm{~A}_{0.6} \mathrm{R}_{0.4}\right)$ because it is a phase between anatase and rutile phases. However, based on the data extracted from XRD and TEM, using a complex compound of glycine with titanium chloride made this possible to have a product with the structure in high purity. The obtained structure has a pseudo-cubed shape.

Anatase phase is illustrated by figure $10 \mathrm{c}$. Anatase as the first phase of $\mathrm{TiO}_{2}$ was obtained 
as a truncated bipyramidal shape constructed by eight $\{101\}$ and two $\{001\}$, which is observable by TEM and FESEM image (inserted in figure 10c). According to the databases [48], this type of shape is obtained with hydrated surfaces.

Figure10d provides information about the rutile phase. Rutile generally obtained with no regular shape and this is the most stable phase. However, here, the rutile phase was obtained with truncated bipyramidal shape, and the same as the anatase phase, with hydrate surface. All the samples' properties have been taken in the figure.

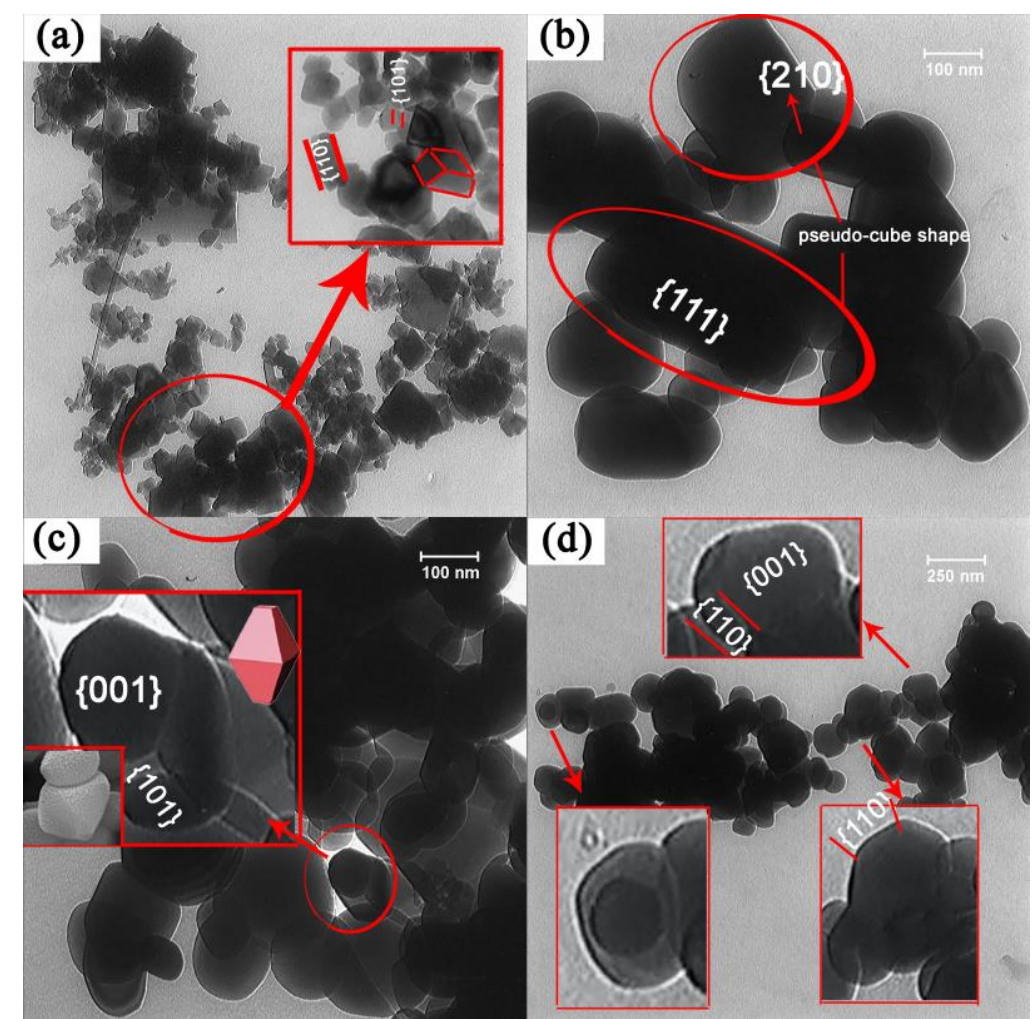

Fig. 10. TEM image of (a) $\mathrm{TiO}_{2}\left(\mathrm{~A}_{0.2} \mathrm{R}_{0.8}\right)$, (b) $\mathrm{TiO}_{2}\left(\mathrm{~A}_{0.6} \mathrm{R}_{0.4}\right)$, (c) $\mathrm{TiO}_{2}(\mathrm{~A})$, and (d) $\mathrm{TiO}_{2}(\mathrm{R})$

Surface analysis. The typical $N_{2}$ adsorption-desorption isotherms (BET method) and the pore distribution curve of samples showed in Fig. 11. The micropores volume has been calculated in the P/Po range of 0-0.990 to collect information about the genesis of porosity (Fig.11a). BET analysis has been used to investigate the surface activity of the samples (Fig.11b), in addition, to determine pore diameter, volume and distribution BJH method have been carried out (Fig. 11c). Furthermore, Langmuir plot, which provides a mean of determining surface area according to monolayer coverage of the solid surface through the adsorptive, has been considered (Fig. 11d). DeBoer t-plot has also been done to determine the external surface area and micropore volume of microporous materials. This plot is according to standard isotherm and thickness curves that describe the statistical thickness of the of adsorptive on a non-porous reference surface (Fig. 11e). The relationship between the 
pore shape and the adsorption-desorption isotherm is $\mathrm{H}_{3}$. These materials have slit-shaped pores. Because of the tensile strength effect, which probably happens for $\mathrm{N}_{2}$ at $77 \mathrm{~K}$ in the pressure between 0.4 and 0.45 , the desorption curve of $\mathrm{H}_{3}$ hysteresis contains a slope related to the force on the hysteresis loop. Also, according to the IUPAC classification, they seem to belong to the type III, which they should be characteristic of macroporous adsorbents, having pore sizes exceeding $50.0 \mathrm{~nm}$. However, the result provided much less than $50.0 \mathrm{~nm}$ (Table 6), and according to the data, they are characteristic of adsorbents that are mesoporous [49], which classified as IV or V. Classification as model V is more logical due to the appearance schematic and it is more logical than the model IV. Thee is also another study on the classification of the pore size, which recently provided by Mays[50], and according to his accurate investigation, the obtained nanoparticles can be also classified as super-nanopore (10-100nm).

The specific surface activity of the samples has been also determined separately by BET analysis (Table 6).

Adsorption is a phenomenon, which depends on the adsorbate on the adsorbent. Langmuir is one of the methods, which can describe the distribution of metal ion such as titanium between two phases of liquid and solid. According to this method, monolayer adsorption on the surface holding a limit number of adsorption site of identical strategies with no transmigration of adsorbate in the plane surface [51]. After filling the site, adsorption will not happen to the site. It illustrates that the surface has no more volume and it is saturated. The data obtained from this analysis can be seen in table 6 .
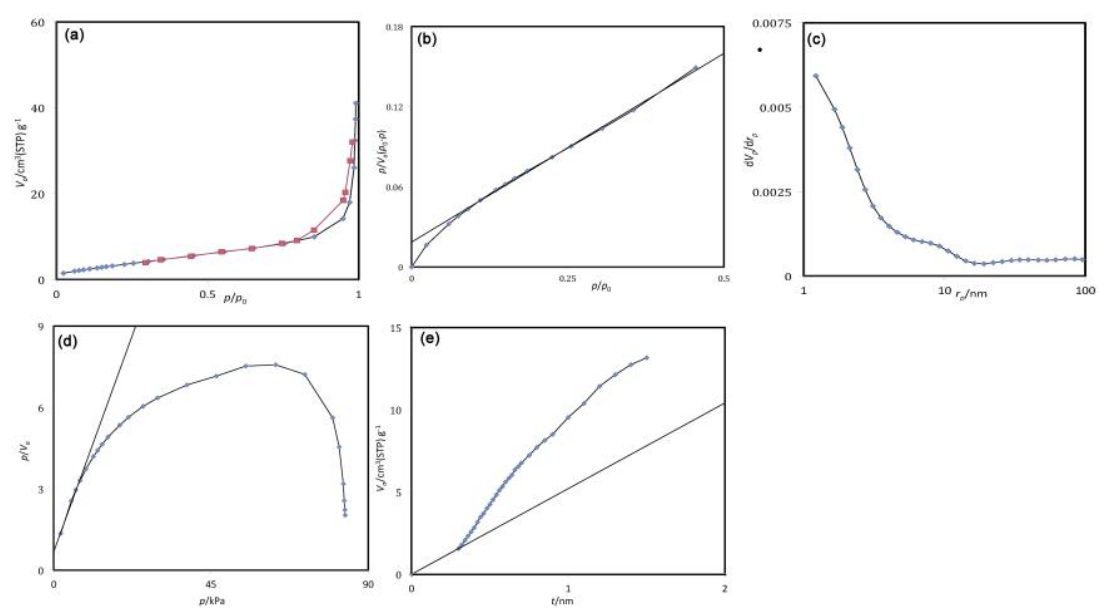

Fig.11. Chemical physical properties of rutile sample; (a) micropores volume, (b) BET analysis, (c) BJH method, (d) Langmuir plot, and (e) DeBoer t-plot 
Table 6. Physical-chemical properties of the samples

\begin{tabular}{|c|c|c|c|c|}
\hline \multicolumn{5}{|c|}{ BET Analysis } \\
\hline Parameters & $\begin{array}{c}\mathrm{TiO}_{2} \\
\left(\mathbf{A}_{0.2} \mathbf{R}_{0.8}\right) \\
\end{array}$ & $\begin{array}{c}\mathrm{TiO}_{2} \\
\left(\mathrm{~A}_{0.6} \mathbf{R}_{0.4}\right)\end{array}$ & $\mathrm{TiO}_{2}(\mathrm{~A})$ & $\mathrm{TiO}_{2}(\mathrm{R})$ \\
\hline $\mathrm{V}_{\mathrm{m}}\left(\mathrm{cm}^{3}(\mathrm{STP}) \mathrm{g}^{-1}\right)$ & 7,0373 & 2,5958 & 4,1705 & 3,3219 \\
\hline$a_{\mathrm{s}, \mathrm{BET}}\left(\mathrm{m}^{2} \mathrm{~g}^{-1}\right)$ & 30,63 & 11,298 & 18,152 & 14,458 \\
\hline $\mathrm{C}$ & 9,8457 & 26,352 & 10,938 & 16,18 \\
\hline $\begin{array}{l}\text { Total pore volume } \\
\left(\mathrm{cm}^{3} \mathrm{~g}^{-1}\right)\end{array}$ & 0,1433 & 0,070965 & 0,064058 & 0,059361 \\
\hline $\begin{array}{l}\text { Mean pore diameter } \\
(\mathrm{nm})\end{array}$ & 18,709 & 25,124 & 14,116 & 16,423 \\
\hline \multicolumn{5}{|c|}{ BJH Analysis } \\
\hline Parameters & $\begin{array}{c}\mathrm{TiO}_{2} \\
\left(\mathbf{A}_{0.2} \mathbf{R}_{0.8}\right)\end{array}$ & $\begin{array}{c}\mathrm{TiO}_{2} \\
\left(\mathrm{~A}_{0.6} \mathbf{R}_{0.4}\right)\end{array}$ & $\mathrm{TiO}_{2}(\mathrm{~A})$ & $\mathrm{TiO}_{2}(\mathrm{R})$ \\
\hline$V_{p}\left(\mathrm{~cm}^{3} \mathrm{~g}^{-1}\right)$ & 0,1512 & 0,072623 & 0,066315 & 0,060265 \\
\hline$r_{p, p e a k}($ Area $)(\mathrm{nm})$ & 1,22 & 1,22 & 1,22 & 1,22 \\
\hline$a_{p}\left(m^{2} g^{-1}\right)$ & 49,364 & 16,94 & 21,813 & 16,279 \\
\hline \multicolumn{5}{|c|}{ Langmuir Analysis } \\
\hline Parameters & $\begin{array}{c}\mathrm{TiO}_{2} \\
\left(\mathbf{A}_{0.2} \mathbf{R}_{0.8}\right) \\
\end{array}$ & $\begin{array}{c}\mathrm{TiO}_{2} \\
\left(\mathbf{A}_{0.6} \mathbf{R}_{0.4}\right) \\
\end{array}$ & $\mathrm{TiO}_{2}(\mathrm{~A})$ & $\mathrm{TiO}_{2}(\mathrm{R})$ \\
\hline $\mathrm{V}_{\mathrm{m}}\left(\mathrm{cm}^{3}(\mathrm{STP}) \mathrm{g}^{-1}\right)$ & 4,4766 & 2,3251 & 2,7007 & 2,8225 \\
\hline$a_{s, \text { Lang }}\left(m^{2} g^{-1}\right)$ & 19,484 & 10,12 & 11,755 & 12,285 \\
\hline $\mathrm{B}$ & 0,4004 & 0,6896 & 0,7635 & 0,5136 \\
\hline \multicolumn{5}{|c|}{ DeBoer t plot Analysis } \\
\hline Parameters & $\begin{array}{c}\mathrm{TiO}_{2} \\
\left(\mathbf{A}_{0.2} \mathbf{R}_{0.8}\right) \\
\end{array}$ & $\begin{array}{c}\mathrm{TiO}_{2} \\
\left(\mathrm{~A}_{0.6} \mathbf{R}_{0.4}\right) \\
\end{array}$ & $\mathrm{TiO}_{2}(\mathrm{~A})$ & $\mathrm{TiO}_{2}(\mathrm{R})$ \\
\hline$a_{1}\left(m^{2} g^{-1}\right)$ & 144,47 & 7,3396 & 7,6368 & 8,0244 \\
\hline $\mathrm{V}_{1}\left(\mathrm{~cm}^{3} \mathrm{~g}^{-1}\right)$ & 0 & 0 & 0 & 0 \\
\hline $\mathrm{a}_{2}\left(\mathrm{~m}^{2} \mathrm{~g}^{-1}\right)$ & 17,869 & - & 6,3449 & - \\
\hline$V_{2}\left(\mathrm{~cm}^{3} \mathrm{~g}^{-1}\right)$ & 0,127 & - & 0,015247 & - \\
\hline $2 \mathrm{t}(\mathrm{nm})$ & 1,9945 & - & 23,458 & - \\
\hline
\end{tabular}

UV-Vis absorption. To calculate the energy bandgap of the samples, UV-Vis spectroscopy, between 200 and $800 \mathrm{~nm}$, was carried out (Fig. 12). According to the results, maximum absorption was different for each sample; $\mathrm{TiO}_{2}\left(\mathrm{~A}_{0.2} \mathrm{R}_{0.8}\right)$, anatase, rutile $(240 \mathrm{~nm})$, and $\mathrm{TiO}_{2}$ $\left(\mathrm{A}_{0.6} \mathrm{R}_{0.4}\right)(390 \mathrm{~nm})$, which illustrate the absorption, occurred in the UV region (200-400nm) and based on the nature of titanium dioxide, this is a common result.

The energy bandgap of the samples was calculated by the Tauc plot (2);

$$
\alpha=\alpha_{0}\left(h v-E_{g}\right) n / h v
$$

Where $\alpha$ is Absorption coefficient, hv is the photon energy, $\alpha_{0}, \mathrm{~h}$ is the constants, Eg is the optical bandgap of the material and $\mathrm{n}$ is between 0.5 and 3 (it depends on the electronic transition).

The energy band gap is received from the plot made by the curves of $(\alpha h v)^{2}$ versus hv. The hv value at the intersection point of the tangent and the $\mathrm{x}$-axis is the bandgap. Based on the mentioned method, the result was 5.1, 3.1, 5, and $5 \mathrm{eV}$ for $\mathrm{TiO}_{2}\left(\mathrm{~A}_{0.2} \mathrm{R}_{0.8}\right), \mathrm{TiO}_{2}\left(\mathrm{~A}_{0.6} \mathrm{R}_{0.4}\right)$, anatase, and rutile respectively (Fig. 13). 
(a) $)^{100}$

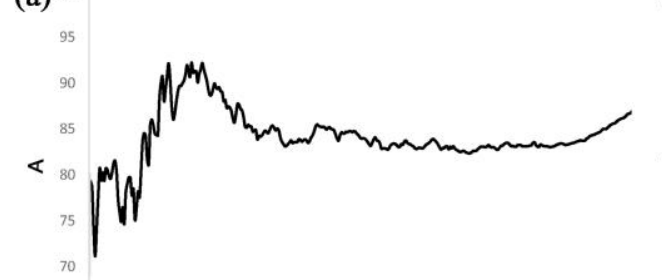

(c)
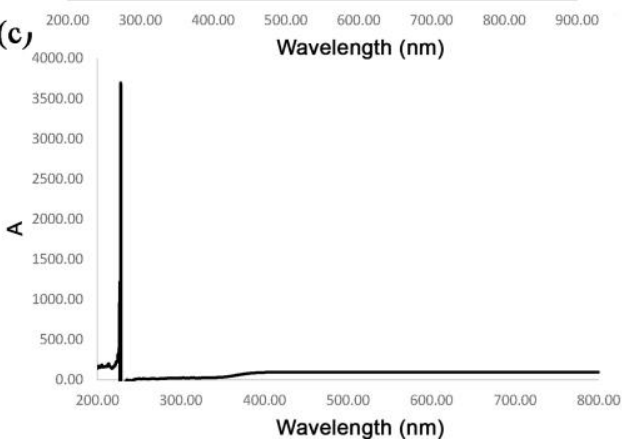

(b) $)^{120.00}$
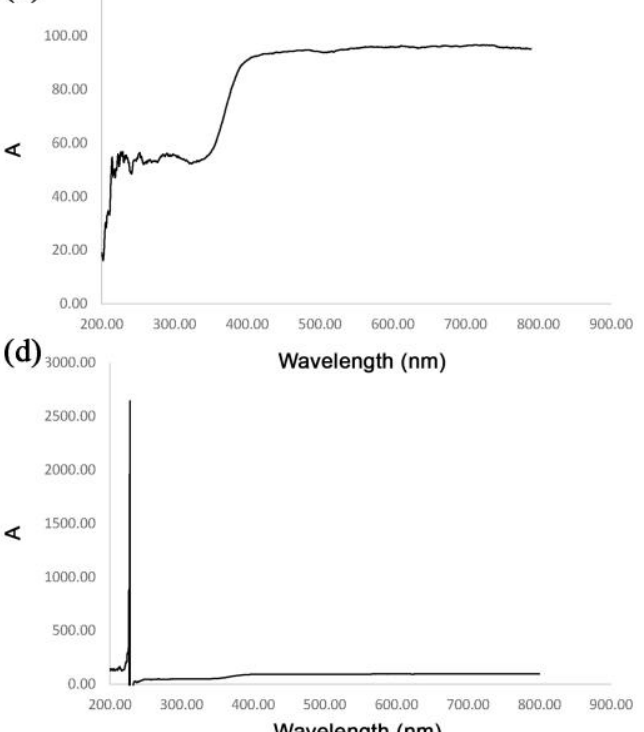

Fig. 12. UV-Vis spectroscopy of (a) $\mathrm{TiO}_{2}\left(\mathrm{~A}_{0.2} \mathrm{R}_{0.8}\right)$, (b) $\mathrm{TiO}_{2}\left(\mathrm{~A}_{0.6} \mathrm{R}_{0.4}\right)$, (c) anatase, and (d) rutile
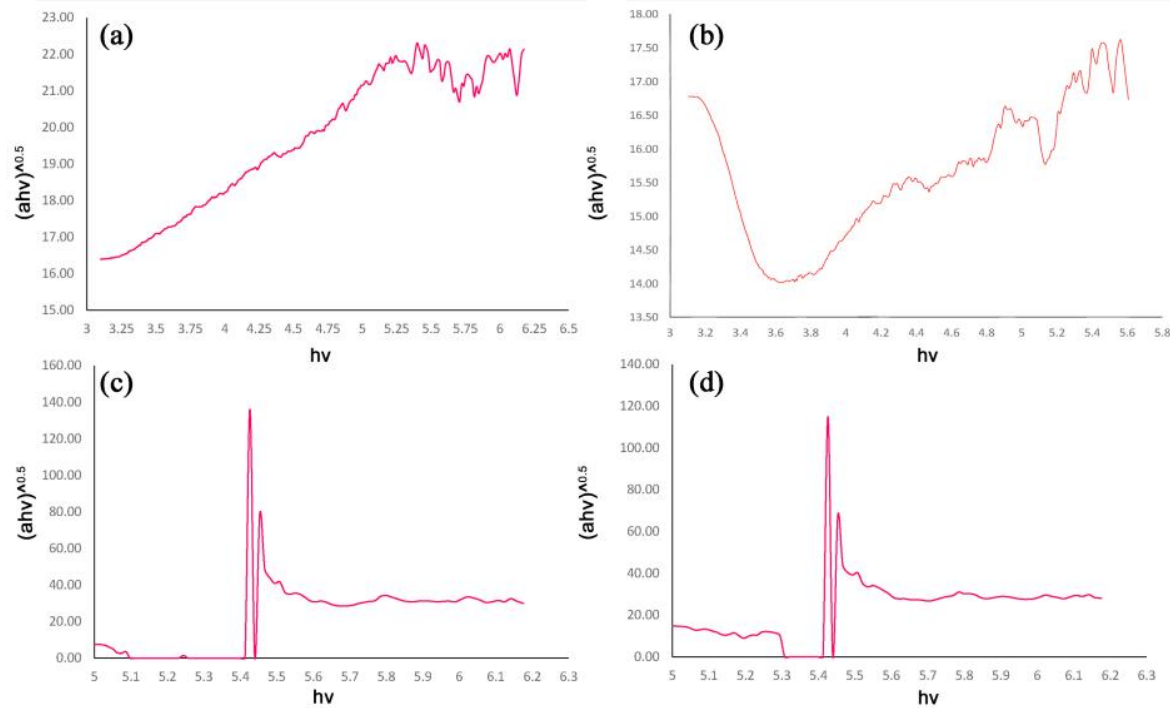

Fig. 13. Energy-band gap of (a) $\mathrm{TiO}_{2}\left(\mathrm{~A}_{0.2} \mathrm{R}_{0.8}\right)$, (b) $\mathrm{TiO}_{2}\left(\mathrm{~A}_{0.6} \mathrm{R}_{0.4}\right)$, (c) anatase, and (d) rutile

\section{Photocatalytic activity of various forms of $\mathrm{TiO}_{2}$ catalysts}

To evaluate and compare the photocatalytic efficiency of the various forms of homeprepared $\mathrm{TiO}_{2} \mathrm{~S}$, the photo-oxidation reaction of 4-chlorobenzyl alcohol is carried out as a model reaction. Acetonitrile and water have been tested as solvents for the partial photooxidation reaction of 4-colours-benzyl alcohol under $8 \mathrm{~h}$ of UV light irradiation. Among solvents, acetonitrile behaves as the best medium for $99 \%$ selective yield of 4-cholorobenzaldehyde, which no significant over oxidation to the corresponding carboxylic acids, 
were detected. Whereas, in the case of water, a small amount of 4-choloro-benzoic acid formation was formed.

To confirm the photocatalytic nature of $\mathrm{TiO}_{2}$, the reaction was carried out without the catalyst and after $20 \mathrm{~h}$ the result showed that no such oxidation occurred in the absence of $\mathrm{TiO}_{2}$ catalyst under UV light irradiation. We have also verified that in the presence of catalyst no reactions occurred in the dark. Therefore, these results confirmed the photocatalytic nature of $\mathrm{TiO}_{2}$ and reveal that both UV irradiation and catalyst needed for the carrying out the photooxidation reaction.

Also, the selectivity and conversion of the synthesized nano- $\mathrm{TiO}_{2} \mathrm{~s}$ on photo-oxidation reaction of benzyl alcohols into benzaldehyde are investigated. Clearly, by extending the irradiation time up to $8 \mathrm{~h}$ the yields of benzaldehyde gradually increased. However, the reaction yield was not changed after $8 \mathrm{~h}$ irradiation.

As mentioned above, the variation of the structure of the $\mathrm{TiO}_{2}$ causes different surface properties and also different photocatalytic activity. Studies on partial photo-oxidation of 4choloro-benzyl alcohol to 4-choloro-benzaldehyde in the presence of home-prepared nano$\mathrm{TiO}_{2} \mathrm{~S}$ indicate a significant difference of the selectivity and conversion for bare rutile, anatase and their composites. Results showed that the efficiency of $\mathrm{TiO}_{2}(\mathrm{R})$ in the aldehyde formation was higher than $\mathrm{TiO}_{2}(\mathrm{~A})$. Moreover, in the case of $\mathrm{TiO}_{2}(\mathrm{R})$ and $\mathrm{TiO}_{2}(\mathrm{~A})$, the rate of the reaction was lower than their composites form. However, the best and highest photocatalytic activity and conversion were observed by the $\mathrm{TiO}_{2}\left(\mathrm{~A}_{0.2} \mathrm{R}_{0.8}\right)$ sample while the lowest one by $\mathrm{TiO}_{2}(\mathrm{~A})$. Therefore, $\mathrm{TiO}_{2}\left(\mathrm{~A}_{0.6} \mathrm{R}_{0.4}\right)$ obtained the highest transformation of 4choloro-benzyl alcohol to 4-choloro-benzaldehyde after $6 \mathrm{~h}$ irradiation (Table 7).

Table 7. Oxidation of 4-chlorobenzylalcohol using home-prepared $\mathrm{TiO}_{2} \mathrm{~S}$

\begin{tabular}{lcc}
\hline \multicolumn{1}{c}{ Sample } & $\begin{array}{c}\text { Time of } \\
\text { irradiation (h) }\end{array}$ & $\begin{array}{c}\text { The yield of aldehyde } \\
\text { generation (\%) }\end{array}$ \\
\hline $\mathrm{TiO}_{2}$ & 8 & 80 \\
$\left(\mathrm{~A}_{0.2} \mathrm{R}_{0.8}\right)$ & & \\
$\mathrm{TiO}_{2}$ & 6 & 87 \\
$\left(\mathrm{~A}_{0.6} \mathrm{R}_{0.4}\right)$ & & 68 \\
$\mathrm{TiO}_{2}(\mathrm{~A})$ & 8 & 75 \\
$\mathrm{TiO}_{2}(\mathrm{R})$ & 8 & \\
\hline
\end{tabular}

To evaluate the generality and applicability of this method, we have examined the photooxidation reaction of substituent-benzyl alcohols in acetonitrile at room temperature under UV irradiation by employing nanocomposite- $\mathrm{TiO}_{2}\left(\mathrm{~A}_{0.6} \mathrm{R}_{0.4}\right)$ (Table 8$)$. The results illustrated that the substituent group on the benzyl ring have a significant role in the photo-oxidation 
reaction. The electron-withdrawing groups that caused low electron density on the $\mathrm{OH}$ group showed a rapid transformation on the $\mathrm{OH}$ into the $\mathrm{CHO}$ group. In contrary, the methoxy substitute in the para position has undesirable effects on the alcohol to aldehyde transformation. Hence, only after $6 \mathrm{~h} \mathrm{UV}$ irradiation in the presence of nanocomposite $\mathrm{TiO}_{2}$ $\left(\mathrm{A}_{0.6} \mathrm{R}_{0.4}\right), 1 \mathrm{mmol} 4$-Nitro-benzyl alcohol was oxidized to $92 \%$ 4-Nitro-benzaldehyde $(0.92$ mmol). Also, the obtained yield for the oxidation of $1 \mathrm{mmol} 4$-choloro-benzyl alcohol to 4choloro-benzaldehyde was $87 \%$. Whereas, in the case of p-Methoxy-benzyl alcohol only $65 \%$ aldehyde formation was observed. It is probably because of the electron-donating nature of the Methoxy group and low electron-withdrawing nature of $-\mathrm{Cl}$ in comparison with the $\mathrm{NO}_{2}$ moiety.

Table 8. Oxidation of various alcohols using nanocomposite- $\mathrm{TiO}_{2}\left(\mathrm{~A}_{0.6} \mathrm{R}_{0.4}\right)$ in acetonitrile.

\begin{tabular}{llll}
\hline Entry & Time (h) & Yield (\%) \\
\hline
\end{tabular}

${ }^{a}$ Yield refers to isolated products by column chromatography; all products were identified by comparing IR, Mass, and TLC with those of authentic samples.

\section{Why is the nanocomposite- $\mathrm{TiO}_{2}\left(\mathrm{~A}_{0.6} \mathbf{R}_{0.4}\right)$ the best?}

The process of the photocatalytic reaction is explained in detail in many types of research and our previous work [15,45,52].

First, it should be explained what properties could affect the photocatalytic and oxidation reactions. Everything comes from the physical properties such as surface activity, total pore volume and pore diameter, besides, the molecular structure of the samples can be also regarded as an important parameter. Furthermore, energy bandgap is also very important; less energy bandgap makes less distance for transferring an electron from the valence to conduct the band to make the photocatalytic reaction.

The larger surface activity provides a better condition for absorbing light to react. According to the BET surface activity, the highest surface activity is related to $\mathrm{TiO}_{2}\left(\mathrm{~A}_{0.8} \mathrm{R}_{0.2}\right)$ 
(30.63 $\left.\mathrm{m}^{2} \mathrm{~g}^{-1}\right)$, while the least is related to $\mathrm{TiO}_{2}\left(\mathrm{~A}_{0.6} \mathrm{R}_{0.4}\right)\left(11.29 \mathrm{~m}^{2} \mathrm{~g}^{-1}\right)$. In another word, although the average pore diameter of the $\mathrm{TiO}_{2}\left(\mathrm{~A}_{0.6} \mathrm{R}_{0.4}\right)$ has the largest amount, pore volume and surface activity is almost the smallest, which shows almost the lowest porosity is related to this sample and it means one of the most effective parameters in the photocatalytic reaction has not been very efficient. It is also confirmed by BJH, Langmuir, and DeBoer t-plot analyses. The next parameter is the molecular structure.

The molecular structures of anatase and rutile phases have been already reported (Fig.14). However, about the two others $\left[\mathrm{TiO}_{2}\left(\mathrm{~A}_{0.8} \mathrm{R}_{0.2}\right), \mathrm{TiO}_{2}\left(\mathrm{~A}_{0.6} \mathrm{R}_{0.4}\right)\right]$, as they are a composition of anatase and rutile phase, the same as Degussa p25, still nobody could find the exact crystalline structure[53], which is due to the lack of enough knowledge and proper methodology for finding the crystalline contents. So due to being both anatase and rutile phases in $\mathrm{TiO}_{2}\left(\mathrm{~A}_{0.8} \mathrm{R}_{0.2}\right)$ and $\mathrm{TiO}_{2}\left(\mathrm{~A}_{0.6} \mathrm{R}_{0.4}\right)$, we consider them as Degussa $\mathrm{p} 25$, as the nearest structure can be purposed so probably the properties will be the same. In both anatase and rutile phases, while the irradiation is occurring $\mathrm{O}-2 \mathrm{p}$ and some of Ti-3d are exist in the valence band, which make a powerful hybridization between the orbitals of $\mathrm{p}$ and $\mathrm{d}$ from $\mathrm{O}$ $2 \mathrm{p}$ and Ti-3d respectively, and indeed, they make the bonding state in the valence band region and provide a bed to transfer of photogenerated holes. In the opposite band, conduct band is composed by $\mathrm{Ti} 3 \mathrm{~d}$ state, which makes interaction with some $\mathrm{O}-2 \mathrm{p}$ and $\mathrm{Ti}-3 \mathrm{~d}$ states. In this band, the main hybridization occurs between Ti-3d and O-2p states, as the antibonding state. However, in the cases $\mathrm{TiO}_{2}\left(\mathrm{~A}_{0.8} \mathrm{R}_{0.2}\right)$ and $\mathrm{TiO}_{2}\left(\mathrm{~A}_{0.6} \mathrm{R}_{0.4}\right)$, there is no knowledge about the exact hybridization and standpoints of the atoms and structures.
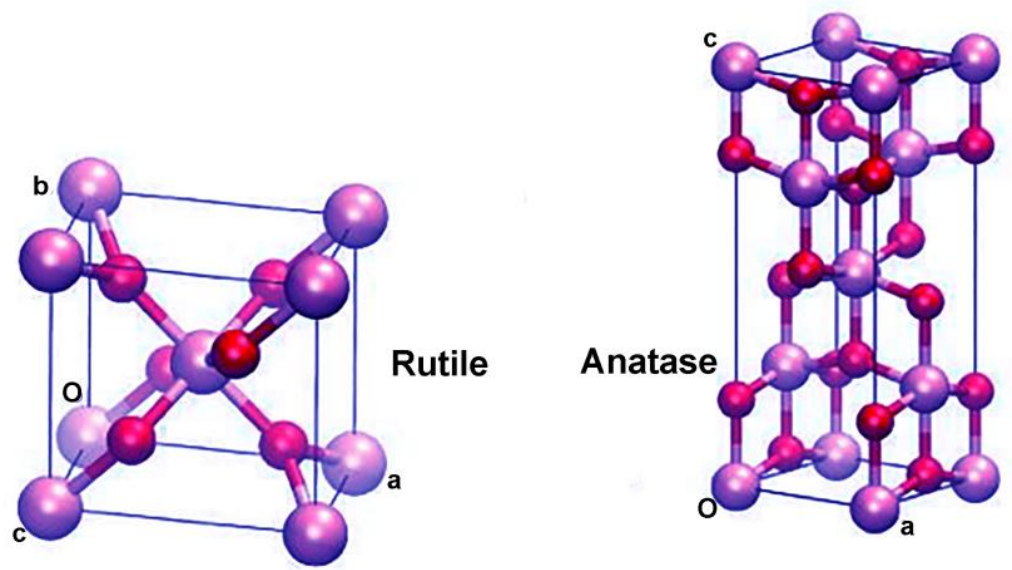

Fig. 14. The molecular structures of rutile and anatase

Energy bandgap is another key factor, which has to be considered. According to the Uv-Vis spectroscopy of the samples and Tauc's plot, the smallest energy bandgap is related to $\mathrm{TiO}_{2}$ $\left(\mathrm{A}_{0.6} \mathrm{R}_{0.4}\right)$ with around $3 \mathrm{eV}$, while others were obtained around the same amount of $5 \mathrm{eV}$ (Fig. 
15). It means the electrons in the valence band of $\mathrm{TiO}_{2}\left(\mathrm{~A}_{0.6} \mathrm{R}_{0.4}\right)$ need to take less energy (almost half compare to other samples) to get the conducting band, so more electron have this possibility to get the conducting band to continue the photocatalytic process, in this case, oxidation reaction. And as a result, more holes are created in the valence band. Even the problem, which is too fast recombination in $\mathrm{TiO}_{2}$ when used as photocatalyst [54], will not effective because the process can be continued as fast as it is possible.

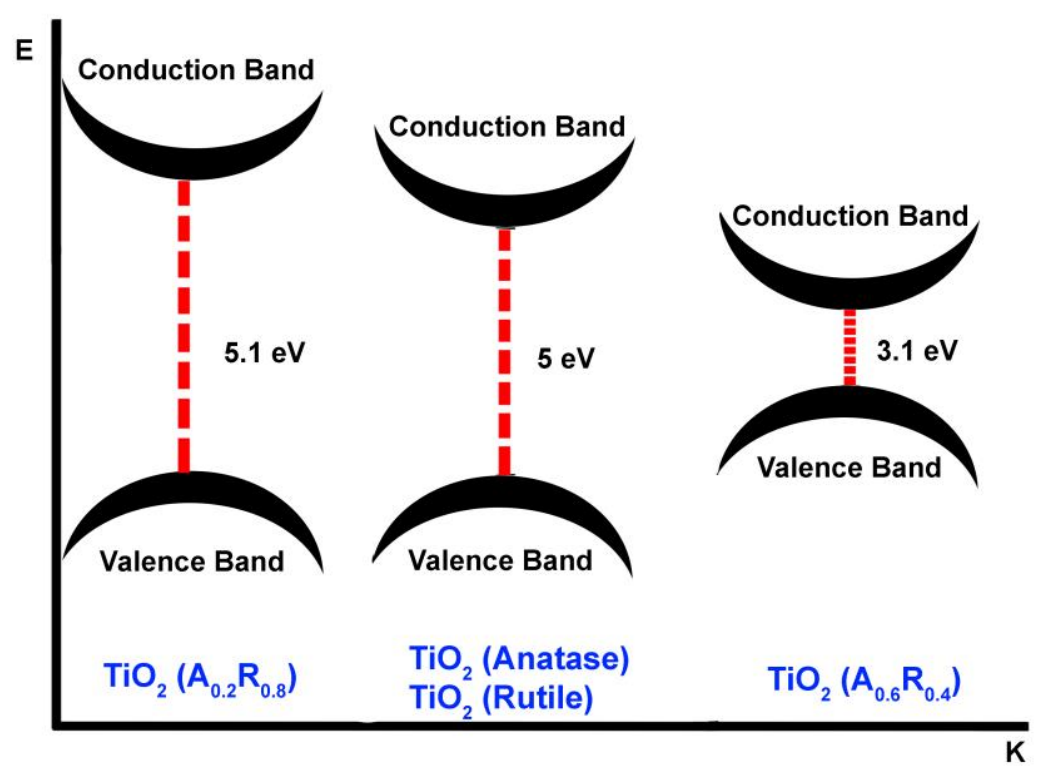

Fig. 15. Comparison of energy bandgap between different samples

\section{Conclusion}

Different derivatives of acid amino in different groups were used to coordinate titanium chloride (III) as a method to control and synthesis $\mathrm{TiO}_{2}$ in different phases and structures. Complex compounds of glycine with titanium chloride (III) gives the $\mathrm{TiO}_{2}$ at the least temperature. $\mathrm{TiO}_{2}\left(\mathrm{~A}_{0.8} \mathrm{R}_{0.2}\right), \mathrm{TiO}_{2}\left(\mathrm{~A}_{0.6} \mathrm{R}_{0.4}\right)$, anatase, and rutile were obtained through thermal decomposing the mentioned complex. The partial selective photocatalytic- oxidation of benzyl alcohols oxidation into corresponding benzaldehyde was investigated. The reaction carried out under UV irradiation in the present of home-prepared-nano- $\mathrm{TiO}_{2} \mathrm{~s}$. The use of UV-visible light to drive oxidation transformations provides a sustainable pathway for green synthesis. The results indicate that the selective photocatalytic oxidation of benzyl alcohols into corresponding aldehydes under UV light irradiation proceeded at high conversion and selectivity. It was found that the efficiency of the obtained $\mathrm{TiO}_{2}\left(\mathrm{~A}_{0.6} \mathrm{R}_{0.4}\right)$ in photo-oxidation of benzyl alcohols into benzaldehydes show high selectivity. These results confirm that the 
oxidation properties of $\mathrm{TiO}_{2}\left(\mathrm{~A}_{0.6} \mathrm{R}_{0.4}\right), \mathrm{TiO}_{2}\left(\mathrm{~A}_{0.2} \mathrm{R}_{0.8}\right)$ are better than of bare rutile and anatase $\mathrm{TiO}_{2}$. Moreover, the photocatalyst can be reused without any loss in selectivity and efficiency. Finally, it can be recommended that $\mathrm{TiO}_{2}\left(\mathrm{~A}_{0.6} \mathrm{R}_{0.4}\right)$ is a selective photocatalyst for the partial photo-oxidation reaction of benzyl alcohols into corresponding aldehydes.

Also, it should be mentioned that although surface activity and porosity are two important factors in photocatalytic reactions, reducing energy bandgap can be more effective, which is obtained by controlling the condition to obtain a sample with the almost the same phases of anatase and rutile.

\section{Acknowledgements}

The publication has been prepared with the support of the Peoples' Friendship University (RUDN University program 5-100), and Ferdowsi University of Mashhad research Council

\section{Conflict of interest statement}

The authors declare that they have no conflict of interest.

\section{Research involving human participants and/ or animals}

This chapter does not contain any studies with human participants or animals performed by any of the authors.

\section{Informed consent}

Informed consent was obtained from all individual participants included in the study. 


\section{Reference}

1. H. Ali, R. Golnak, R. Seidel, B. Winter, and J. Xiao, ACS Appl. Nano Mater. 3, 264 (2020).

2. J. Z. Soo, L. C. Chai, B. C. Ang, and B. H. Ong, ACS Appl. Nano Mater. 3, 5743 (2020).

3. C. D. Brubaker, M. A. Davies, J. R. McBride, S. J. Rosenthal, G. K. Jennings, and D.

E. Adams, ACS Appl. Nano Mater. 1, 1377 (2018).

4. N. Katir, N. Marcotte, S. Michlewska, M. Ionov, N. El Brahmi, M. Bousmina, J. P. Majoral, M. Bryszewska, and A. El Kadib, ACS Appl. Nano Mater. 2, 2979 (2019).

5. Y. Absalan, M. A. Ryabov, and O. V. Kovalchukova, Mater. Sci. Eng. C 97, 813 (2019).

6. S. R. ten Brink G-J, Arends IW, Science (80-. ). 287, 1636 (2000).

7. E. J. Nechab M, Einhorn C, Chem. Commun. 1500, (2004).

8. Z. R.-Q. hao L, Zhang B, Xiao X, Gu FL, J. Mol. Catal. A Chem. 420, 82 (2016).

9. K. W. Golub, T. P. Sulmonetti, L. A. Darunte, M. S. Shealy, and C. W. Jones, ACS Appl. Nano Mater. 2, 6040 (2019).

10. S. Chang, C. Liu, Y. Sun, Z. Yan, X. Zhang, X. Hu, and H. Zhang, ACS Appl. Nano Mater. 3, 2302 (2020).

11. S. J. Zhao, X. Zhou, H. B. Li, K. Liang, L. B. Ma, X. X. Fang, T. Zhao, C. Ling, and A. W. Xu, ACS Appl. Nano Mater. 2, 5634 (2019).

12. Z. Zhang, H. Gao, H. Wu, Y. Qian, L. Chen, and J. Chen, ACS Appl. Nano Mater. 1, 6463 (2018).

13. Y. Absalan, O. V.Avramenko, and and O. V. Kovalchukova, Butlerov Commun. 47, 49 (2016).

14. Y. Absalan, I. G. Bratchikova, and O. V. Kovalchukova, J. Mol. Liq. 268, 882 (2018).

15. Y. Absalan, E. A. Fortalnova, N. N. Lobanov, E. V Dobrokhotova, and O. V

Kovalchukova, J. Organomet. Chem. 859, 80 (2018).

16. H. H. Do, D. L. T. Nguyen, X. C. Nguyen, T. H. Le, T. P. Nguyen, Q. T. Trinh, S.

H. Ahn, D. V. N. Vo, S. Y. Kim, and Q. Van Le, Arab. J. Chem. 13, 3653 (2020).

17. I. B. U. I. G.-P. H.Grassian, J. Colloid Interface Sci. 554, 362 (2019).

18. R. Wu, S. Wang, Y. Zhou, J. Long, F. Dong, and W. Zhang, ACS Appl. Nano Mater. 2, 6818 (2019).

19. S. Razmyar, T. Sheng, M. Akter, and H. Zhang, ACS Appl. Nano Mater. 2, 4180 (2019).

20. S. Samanta, S. Khilari, and R. Srivastava, ACS Appl. Nano Mater. 1, 426 (2018).

21. I. C. Amaechi, A. Hadj Youssef, D. Rawach, J. P. Claverie, S. Sun, and A. Ruediger, ACS Appl. Nano Mater. 2, 2890 (2019).

22. Y. Absalan, I. Bratchikova, and O. V.Kovalchukova, Environ. Nanotechnology, Monit. Manag. J. 8, 244 (2017).

23. F. M. Tojo G, Springer Sci. Bus. Media (2006).

24. P. A. Kopylovich MN, Ribeiro AP, Alegria EC, Martins NM, Martins LM, Adv. Organomet. Chem. 91 (2015).

25. Y. Absalan, I. G. Bratchikova, N. N. Lobanov, and O. V. Kovalchukova, J. Mater.

Sci. Mater. Electron. 28, 18207 (2017).

26. et al. Heggo D, Ookawara S, Ohno T, Nakai T, Matsushita Y, Eldin MG, Can. J. Chem. Eng. 98, 119 (2020).

27. H. MA, Surf. Sci. Rep. 66, 185 (2011).

28. et al. Schneider J, Matsuoka M, Takeuchi M, Zhang J, Horiuchi Y, Anpo M, Chem. 
Rev. 114, 9919 (2014).

29. H. U. Courtois C, Eder M, Schnabl K, Walenta CA, Tschurl M, Angew. Chemie Int. Ed. 58, 14255 (2019).

30. G. J. Li C-J, Xu G-R, Zhang B, Appl. Catal. B Environ. 115, 201 (2012).

31. Z. J. Wang Q, Zhang M, Chen C, Ma W, Angew. Chemie Int. Ed. 49, 7976 (2010).

32. et al. Higashimoto S, Kitao N, Yoshida N, Sakura T, Azuma M, Ohue H, J. Catal.

266, 279 (2009).

33. J. Huo, C. Yuan, and Y. Wang, ACS Appl. Nano Mater. 2, 2713 (2019).

34. D. T. Nguyen, C. C. Nguyen, M. St-Jean, S. Chabot, S. Kaliaguine, and T. O. Do, ACS Appl. Nano Mater. 1, 6864 (2018).

35. R. Asapu, N. Claes, R. G. Ciocarlan, M. Minjauw, C. Detavernier, P. Cool, S. Bals, and S. W. Verbruggen, ACS Appl. Nano Mater. 2, 4067 (2019).

36. Y. Shiraishi, S. Toi, S. Ichikawa, and T. Hirai, ACS Appl. Nano Mater. 3, 1612 (2020).

37. W. S. Arbuj SS, Hawaldar RR, Mulik UP, Wani BN, Amalnerkar DP, Mater. Sci.

Eng. B 168, 90 (2010).

38. W. K. Jaimy KB, Baiju K, Ghosh S, J. Solid State Chem. 186, 149 (2012).

39. M. M. Ohno T, Mitsui T, Chem. Lett. 32, 364 (2003).

40. M. W. Buchalska M, Kobielusz M, Matuszek A, Pacia M, Wojtyła S, ACS Catal. 5, 7424 (2015).

41. A. R. Ohtani B, Prieto-Mahaney O, Li D, J. Photochem. Photobiol. A Chem. 216, 179 (2010).

42. V. J. Yamakata A, J. Photochem. Photobiol. C Photochem. Rev. 40, 234 (2019).

43. A. Leifer and E.R.Lippincott, J. Chem SGC 79, 5098 (1957).

44. J. Han and Y. S. Chi, J. Appl. Biol. Chem. 53, 821 (2010).

45. Y. Absalan, I. Bratchikova, and O. V Kovalchukova, Environ. Nanotechnology, Monit. \&\#x0026; Manag. 8, 244 (2017).

46. L. Shen, Z. Xing, J. Zou, Z. Li, X. Wu, Y. Zhang, and Q. Zhu, Nat. Publ. Gr. 1 (2017).

47. Y. Absalan, I. Bratchikova, Labanov, and O. V.Kovalchukova, J. Mater. Sci. Mater. Electron. 28, 18220 (2017).

48. R. Sharma, A. Sarkar, R. Jha, A. Kumar Sharma, and D. Sharma, Int. J. Appl.

Ceram. Technol. ijac. 13439 (2019).

49. Z. A. Alothman, Materials (Basel). 5, 2874 (2012).

50. T. J. Mays, Stud. Surf. Sci. Catal. 160, 57 (2007).

51. B.H.Hameed and T.M.DinA.L.Ahmad, J. Hazard. Mater. 141, 819 (2007).

52. Y. Absalan, I. Bratchikova, Labanov, and O. V.Kovalchukova, J. Mater. Sci. Mater. Electron. 28, 18220 (2017).

53. B. Ohtani, O. O. Prieto-Mahaney, D. Li, and R. Abe, J. Photochem. Photobiol. A Chem. 216, 179 (2010).

54. W. S. Koe, J. W. Lee, W. C. Chong, Y. L. Pang, and L. C. Sim, Environ. Sci. Pollut. Res. 27, 2522 (2020). 
Figures

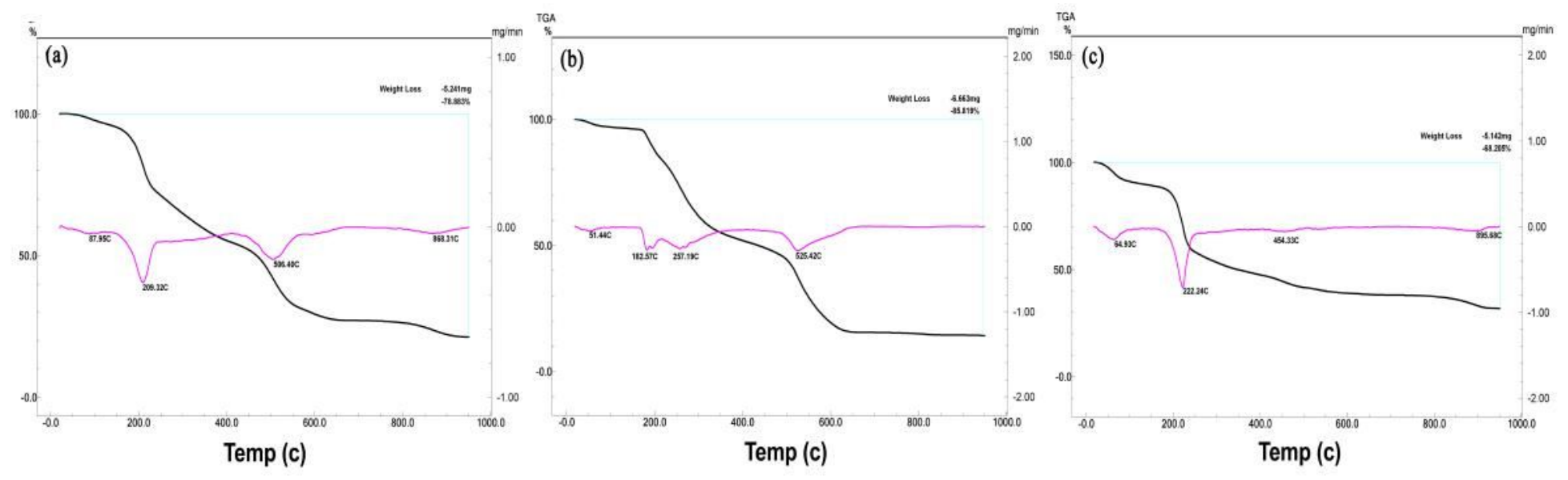

Figure 1

TGA analysis from the obtained complexes; (a) ML1 (b) ML2, and (c) ML3 
(a)
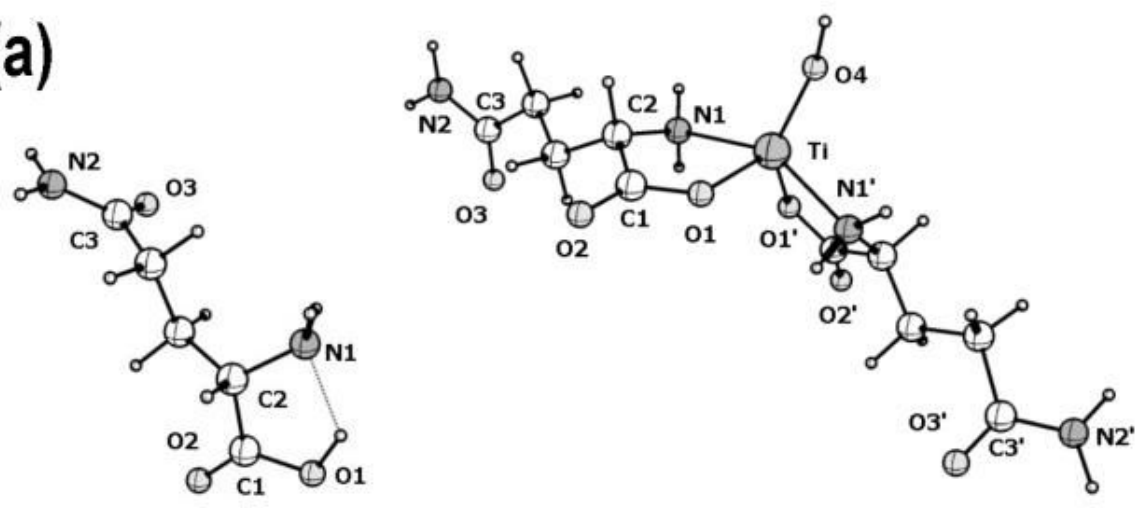

$\mathrm{HL}^{1}\left(\mathrm{a}_{1}\right)$

$\mathrm{Ti}\left(\mathrm{L}^{1}\right)_{2} \mathrm{OH}\left(\mathrm{a}_{2}\right)$

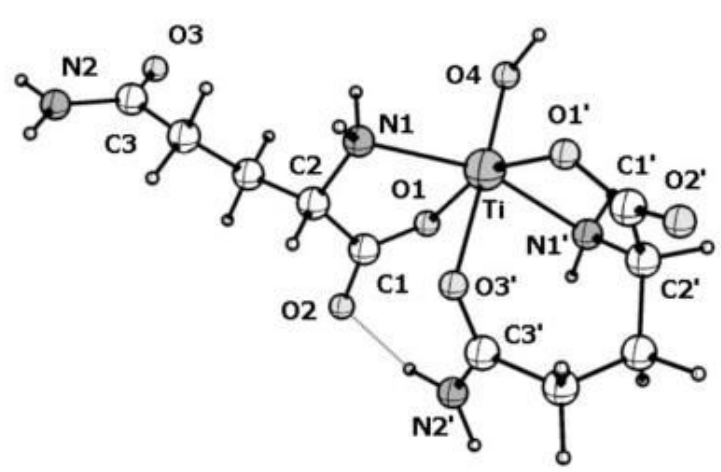

(b)
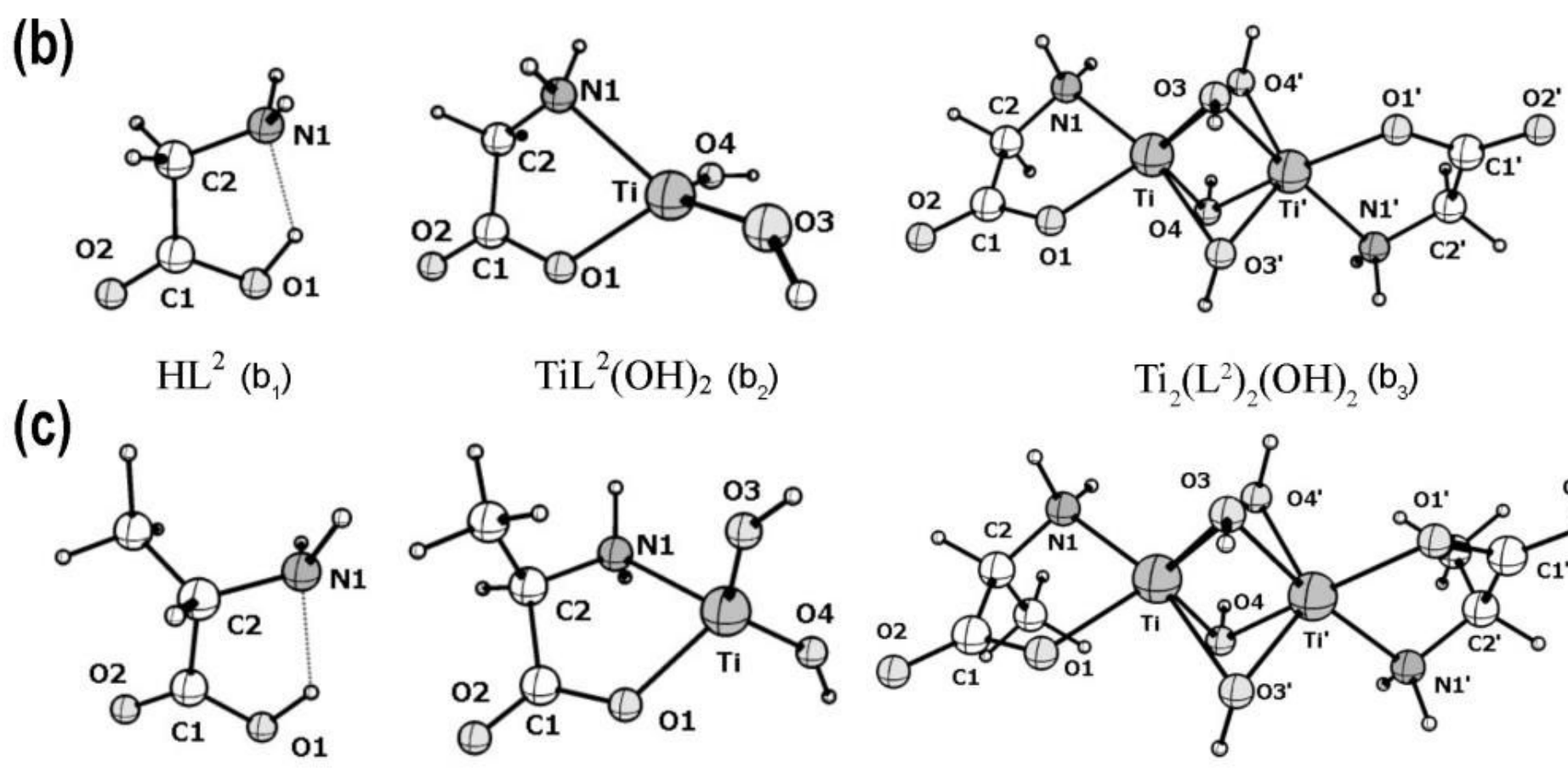

$\mathrm{TiL}^{2}(\mathrm{OH})_{2}\left(\mathrm{~b}_{2}\right)$

$\mathrm{Ti}\left(\mathrm{L}^{1}\right)_{2} \mathrm{OH} \quad\left(\mathrm{a}_{3}\right)$

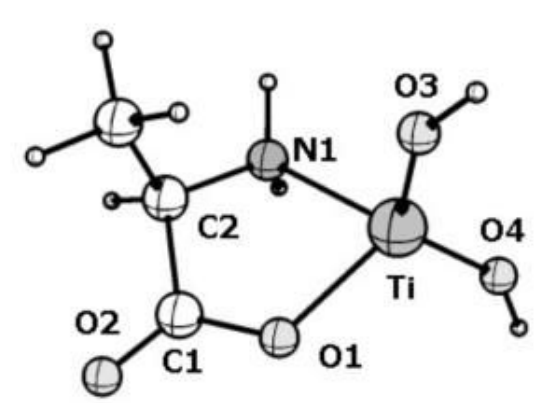

$\mathrm{HL}^{3}\left(\mathrm{c}_{1}\right)$

$\operatorname{TiL}^{3}(\mathrm{OH})_{2}\left(\mathrm{c}_{2}\right)$

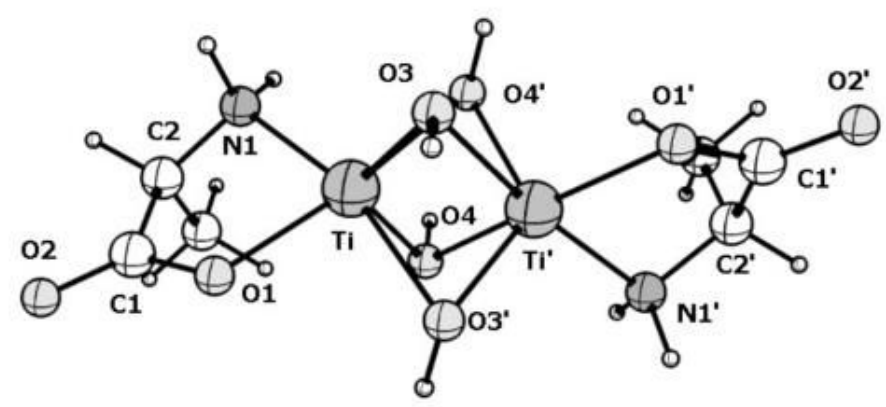

$\mathrm{Ti}_{2}\left(\mathrm{~L}^{2}\right)_{2}(\mathrm{OH})_{2}\left(\mathrm{c}_{3}\right)$

Figure 2

The molecular structure of the molecules according to the calculation by the DFT method 


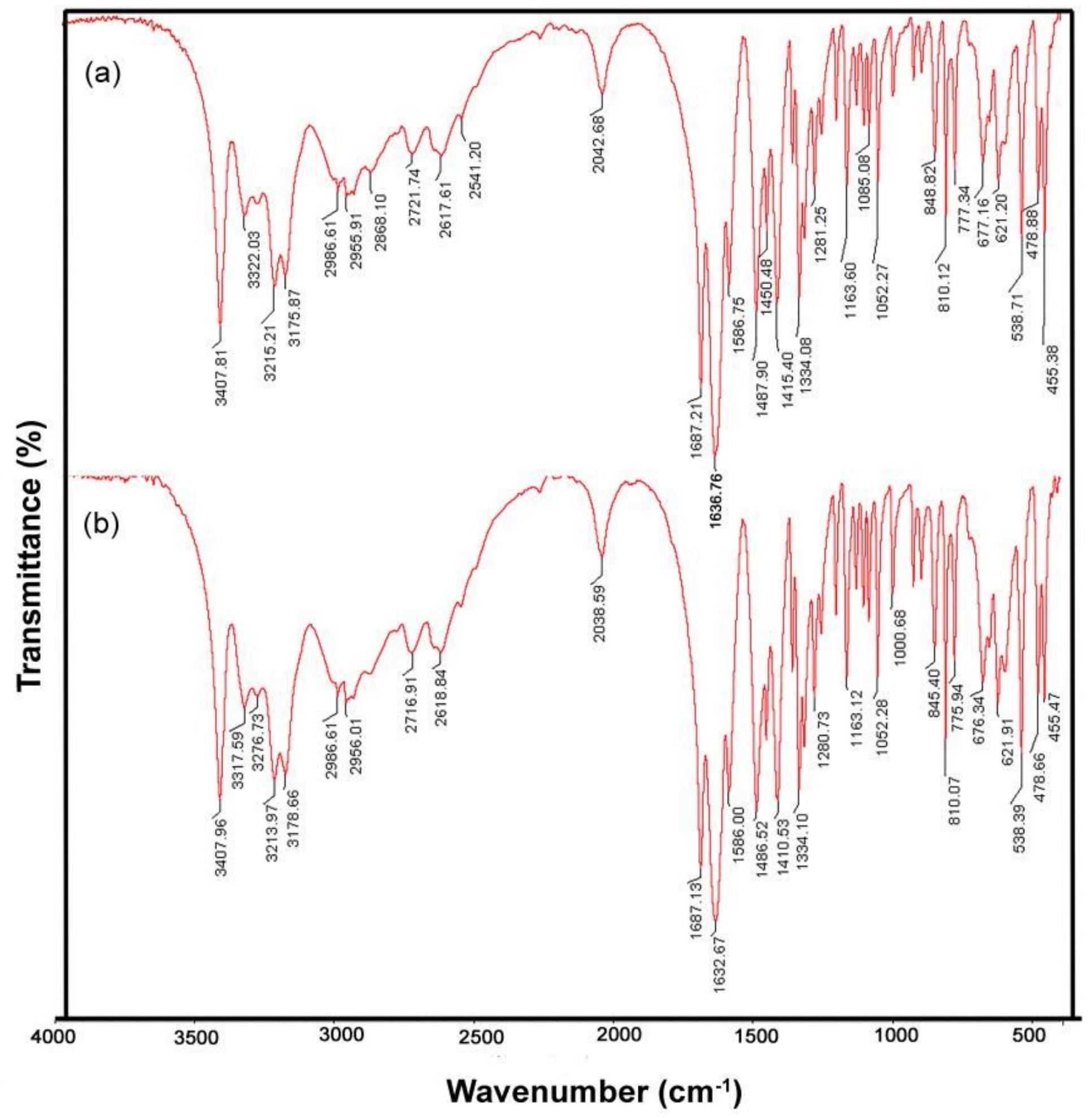

Figure 3

IR spectroscopy of (a) glutamine (L1), and (b) glutamine with titanium chloride (III) (L1+Ti) 


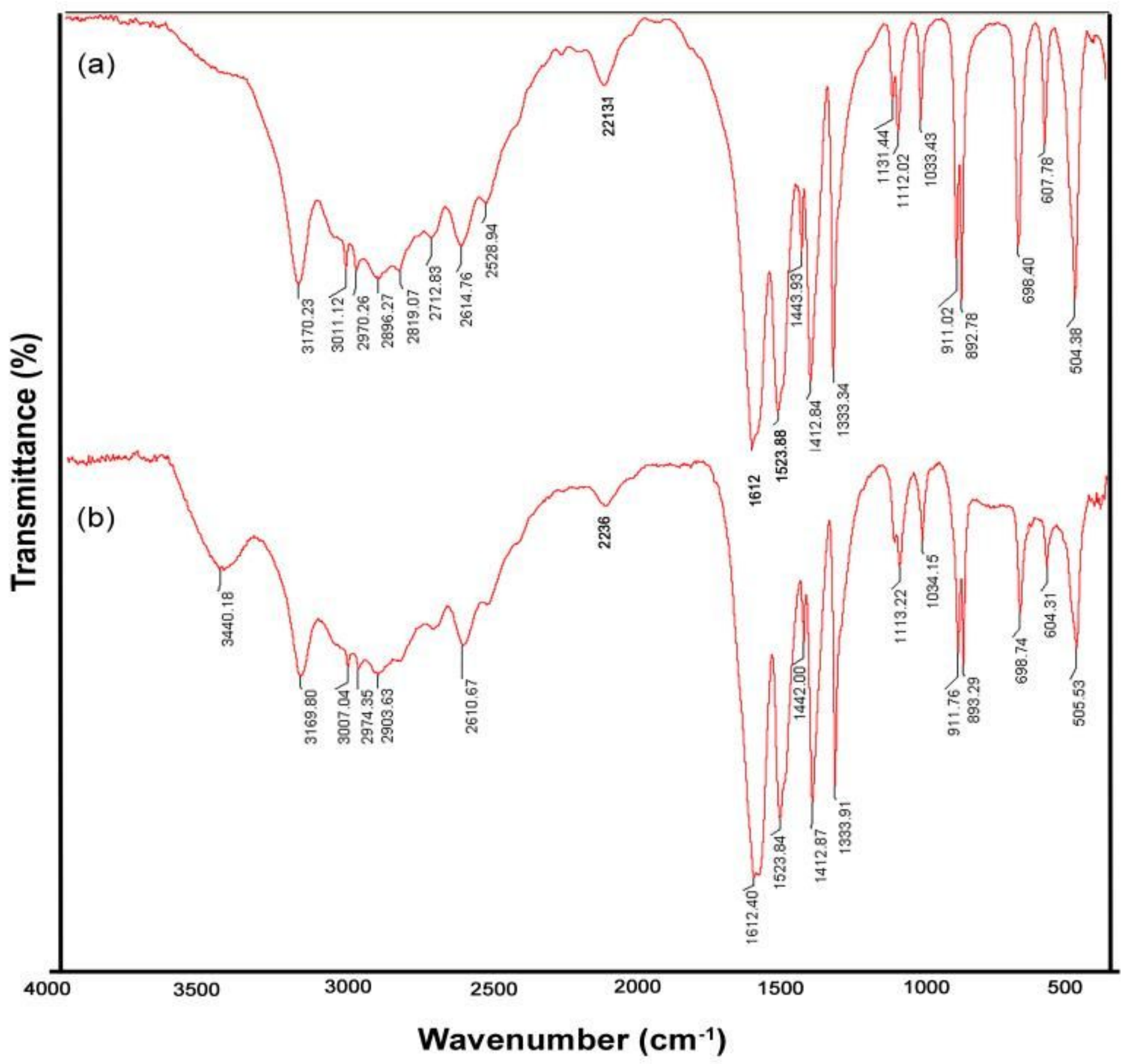

Figure 4

IR spectroscopy of (a) glycine (L2), and (b) glycine with titanium chloride (III) (L2+Ti) 


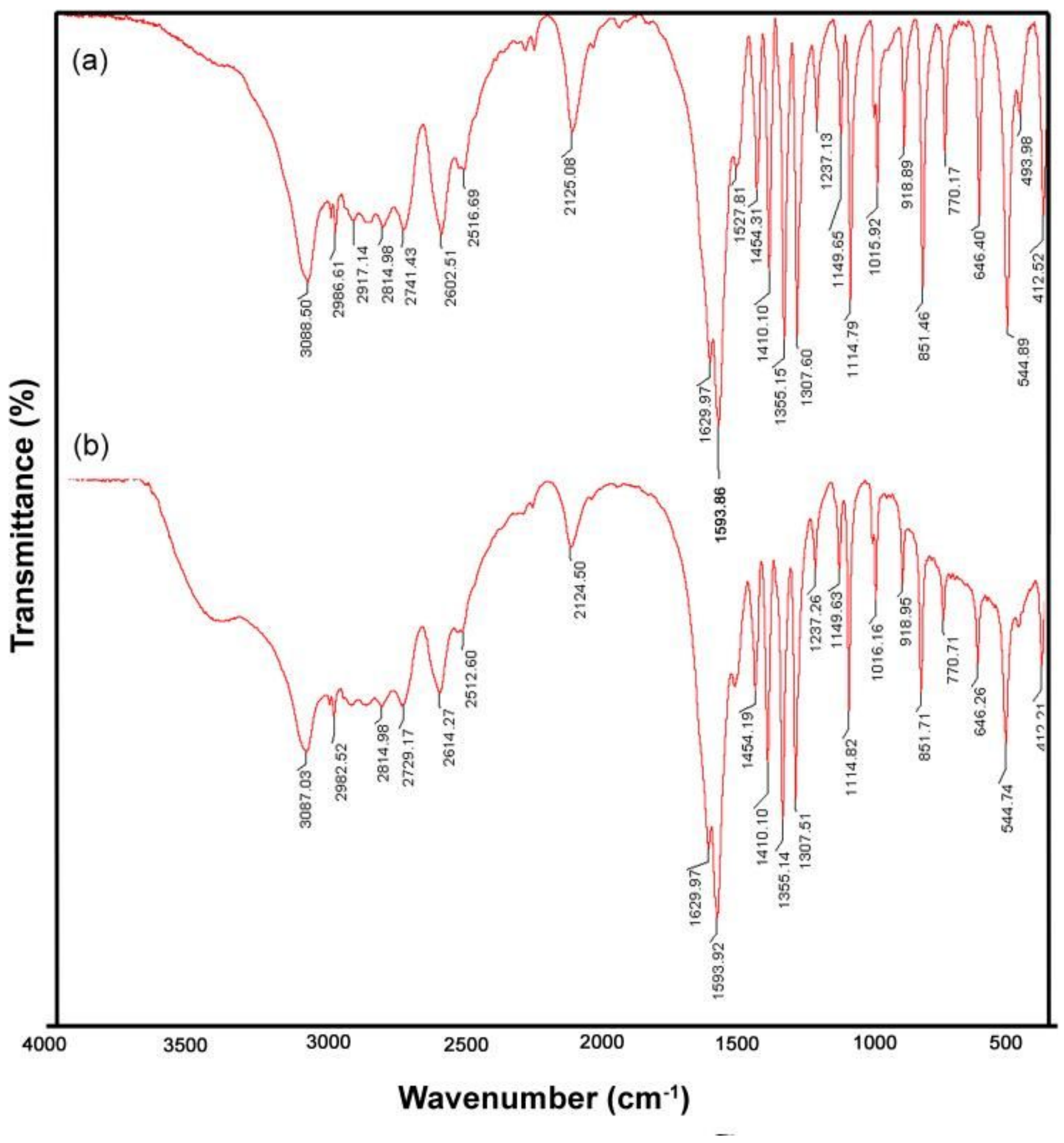

Figure 5

IR spectroscopy of (a) L-Alanine (L3), and (b) L-Alanine with titanium chloride (III) 

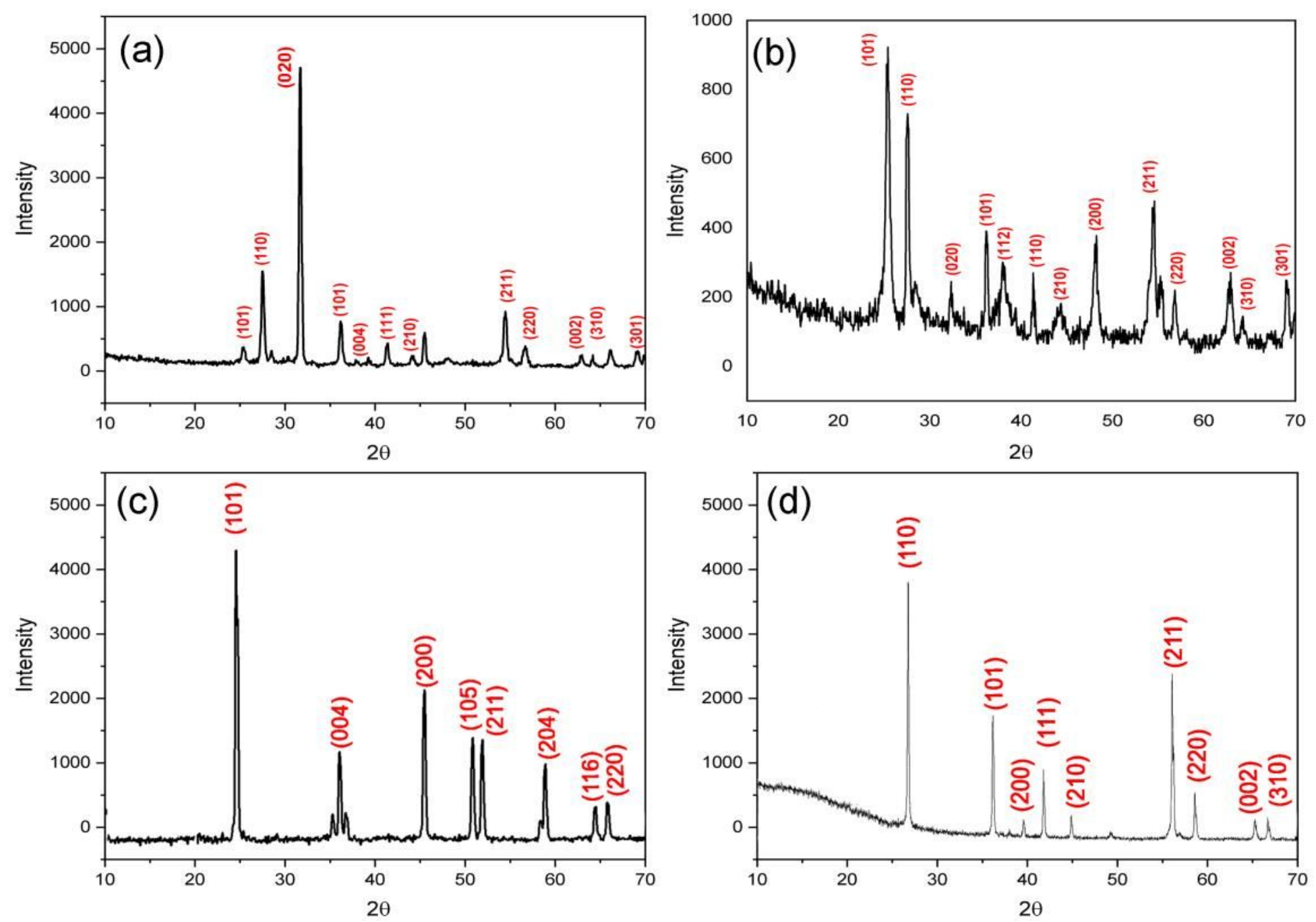

Figure 6

XRD pattern of (a) TiO2 (A0.2R0.8), (b) TiO2 (A0.6R0.4), (c) TiO2 (A), and (d) TiO2 (R) 


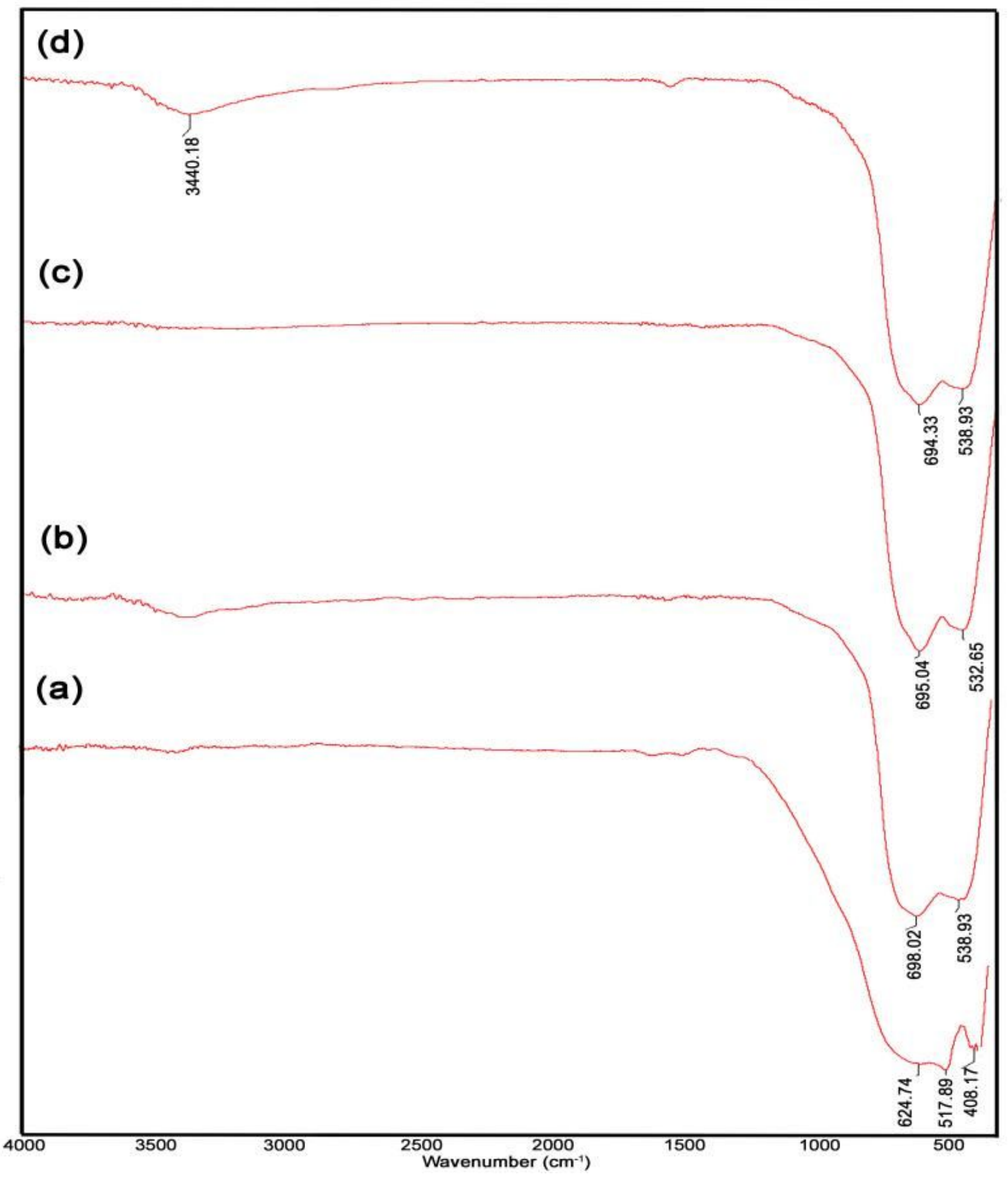

Figure 7

FT-IR spectroscopy of the nanoparticles; (a) TiO2 (A0.2R0.8), (b) TiO2 (A0.6R0.4) (c) TiO2 (A), and (d) $\mathrm{TiO} 2(\mathrm{R})$ 


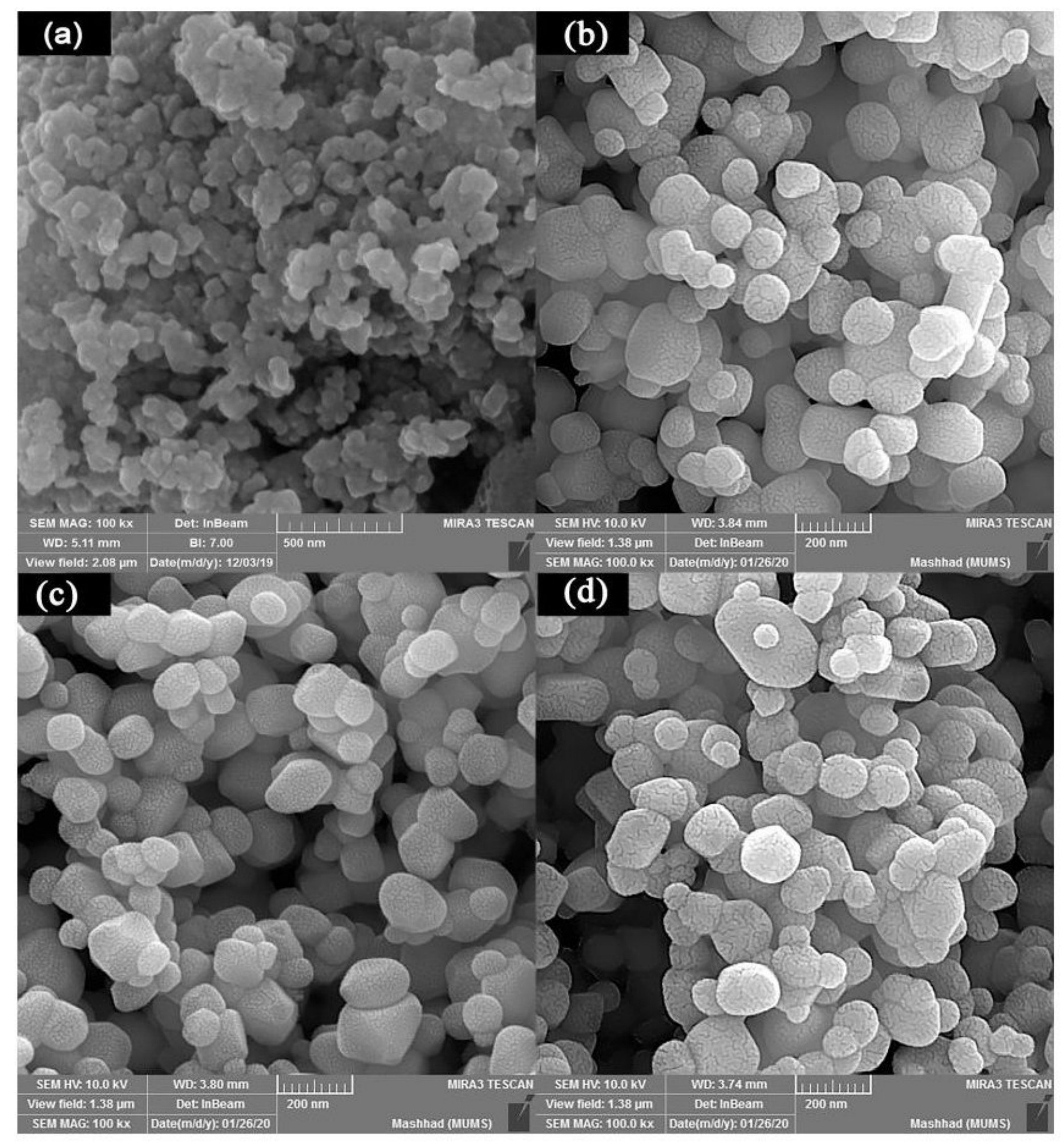

\section{Figure 8}

FESEM image of (a) TiO2 (A0.2R0.8), (b) TiO2 (A0.6R0.4), (c) TiO2 (A), and (d) TiO2 (R) 

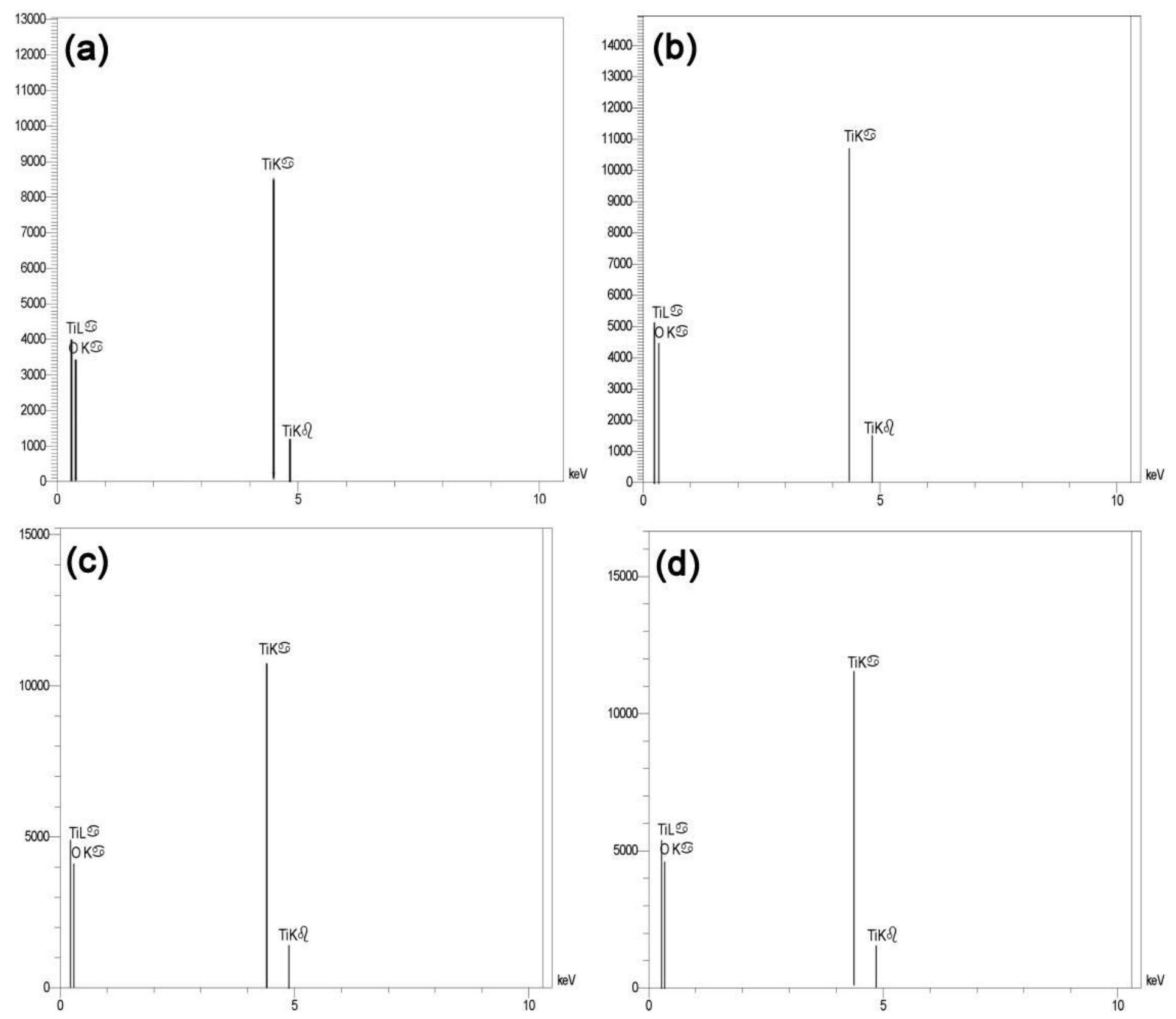

Figure 9

EDX pattern of (a) TiO2 (A0.2R0.8), (b) TiO2 (A0.6R0.4), (c) TiO2 (A), and (d) TiO2 (R) 

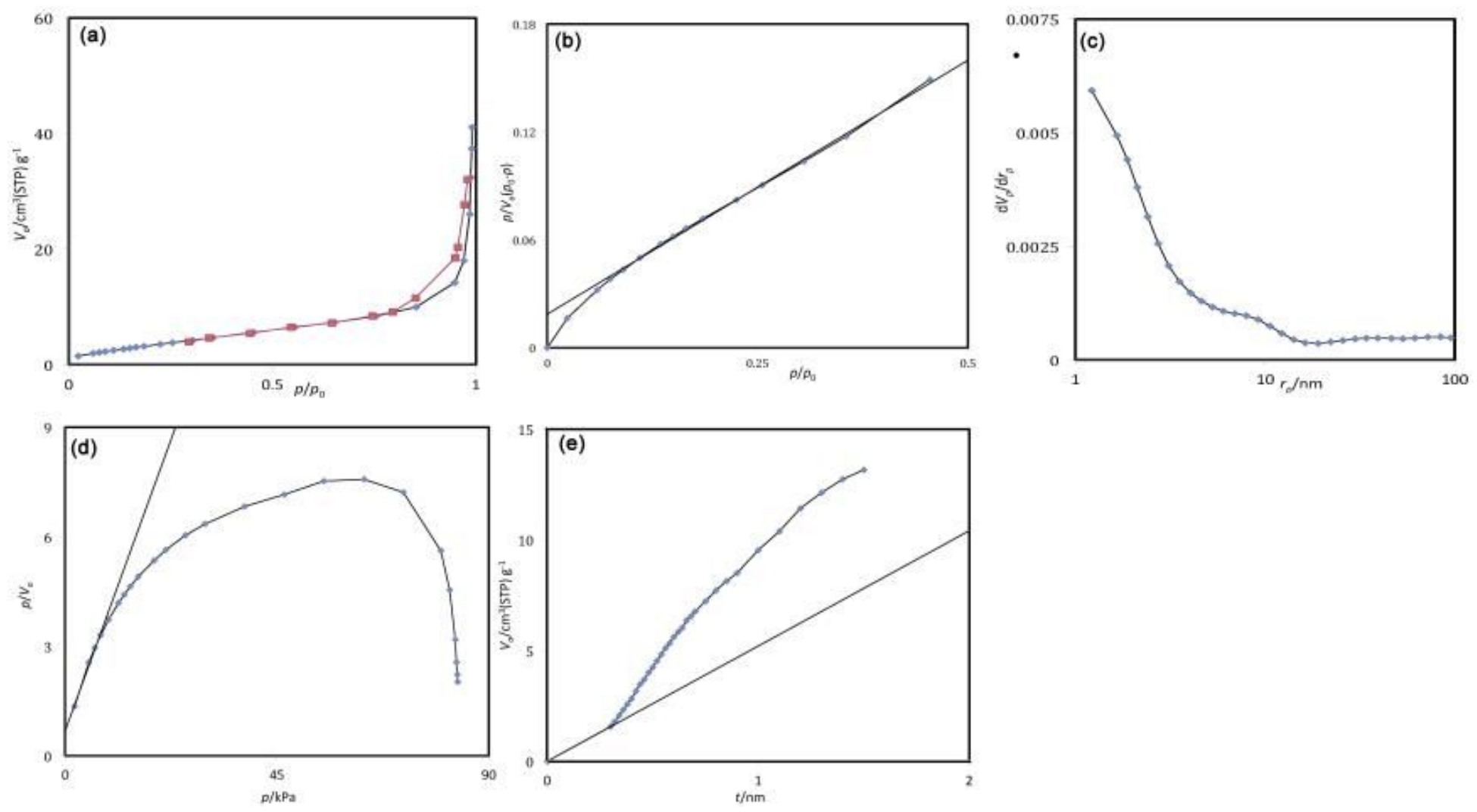

Figure 11

Chemical physical properties of rutile sample; (a) micropores volume, (b) BET analysis, (c) BJH method, (d) Langmuir plot, and (e) DeBoer t-plot 
$\left(\right.$ a) ${ }^{100}$

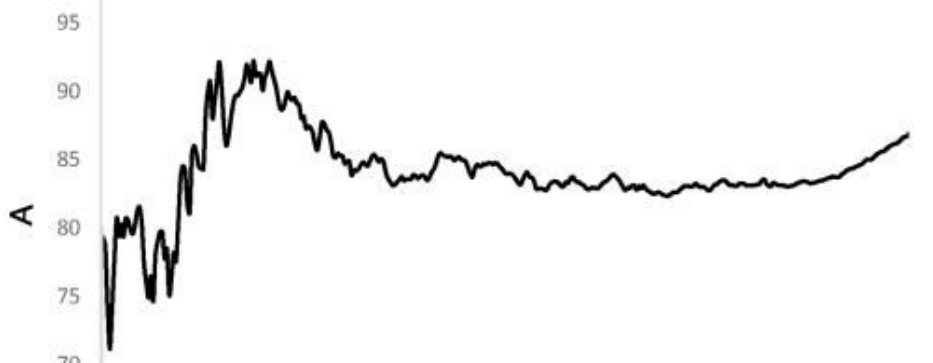

70

65 ,

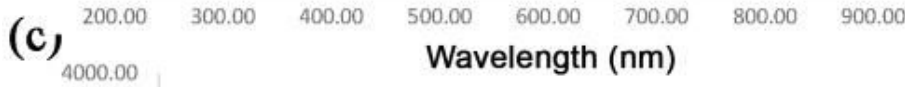

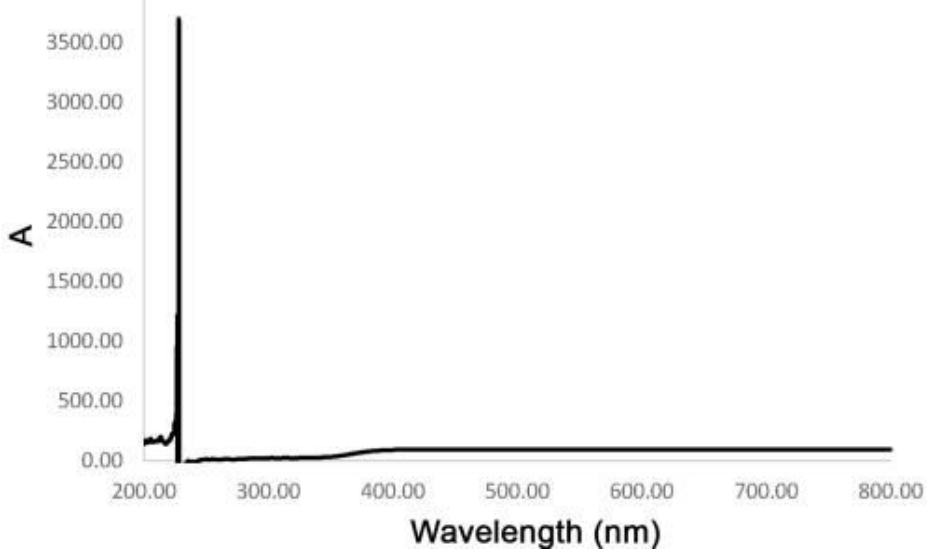

(b) $)^{120.00}$

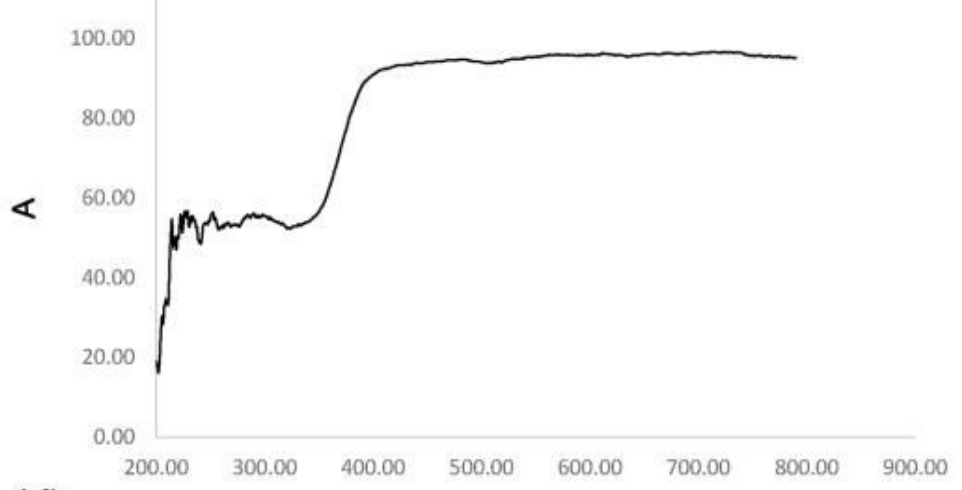

(d)
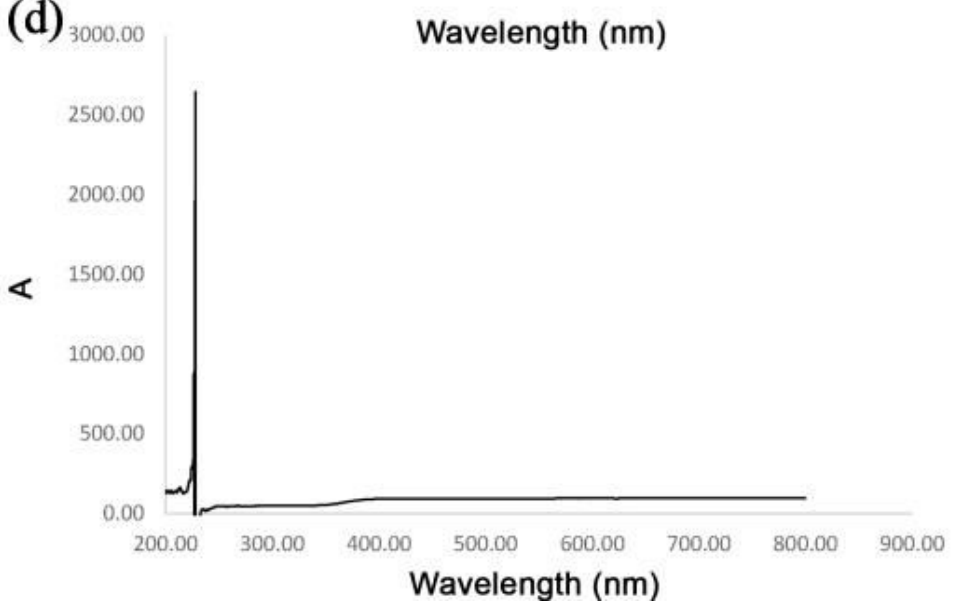

Figure 12

UV-Vis spectroscopy of (a) TiO2 (A0.2R0.8), (b) TiO2 (A0.6R0.4), (c) anatase, and (d) rutile 

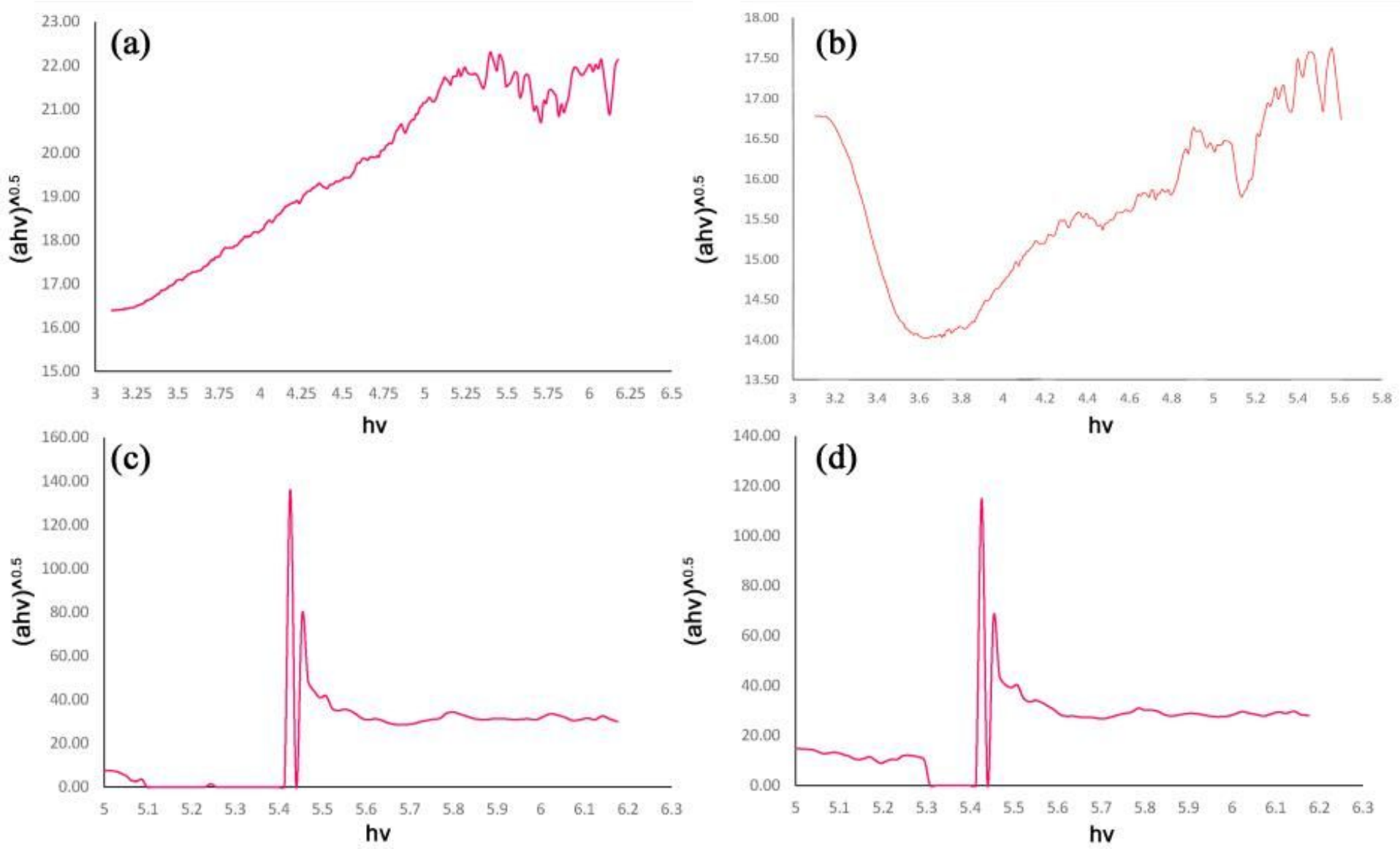

Figure 13

Energy-band gap of (a) TiO2 (A0.2R0.8), (b) TiO2 (A0.6R0.4), (c) anatase, and (d) rutile 


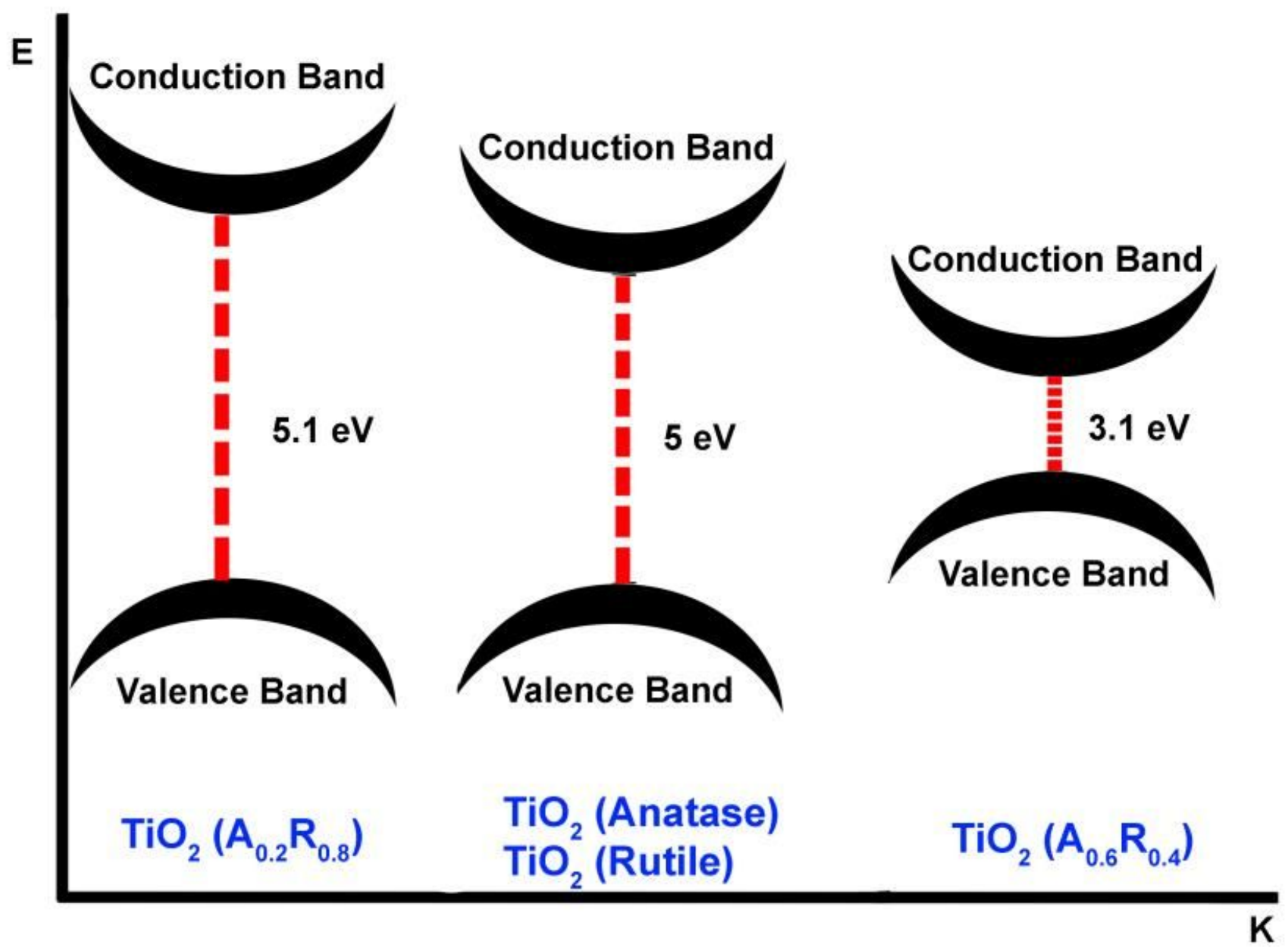

Figure 15

Comparison of energy bandgap between different samples

\section{Supplementary Files}

This is a list of supplementary files associated with this preprint. Click to download.

- GraphicalAbstract.jpg 